\title{
Nicaragua: Ex Post Assessment of Longer-Term Program Engagement
}

This Ex Post Assessment of Longer-Term Program Engagement report on Nicaragua was prepared by a staff team of the International Monetary Fund as background documentation for the periodic consultation with the member country. It is based on the information available at the time it was completed on June 12, 2012. The views expressed in this document are those of the staff team and do not necessarily reflect the views of the government of Nicaragua or the Executive Board of the IMF.

The policy of publication of staff reports and other documents by the IMF allows for the deletion of market-sensitive information.

Copies of this report are available to the public from

International Monetary Fund • Publication Services

$70019^{\text {th }}$ Street, N.W. • Washington, D.C. 20431

Telephone: (202) 623-7430 • Telefax: (202) 623-7201

E-mail: publications@imf.org Internet: http://www.imf.org

\section{International Monetary Fund Washington, D.C.}




\section{INTERNATIONAL MONETARY FUND}

\section{NICARAGUA}

\section{Ex Post Assessment of Longer-Term Program Engagement}

Prepared by an Interdepartmental Staff Team ${ }^{1}$

Approved by the Western Hemisphere and Strategy, Policy, and Review Departments

June 12, 2012

Contents

Page

Executive Summary. 3

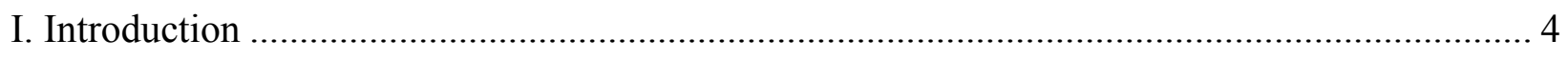

II. A Bird's Eye View of Economic Developments in Nicaragua: 2007-11 ........................... 5

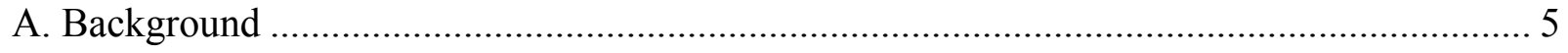

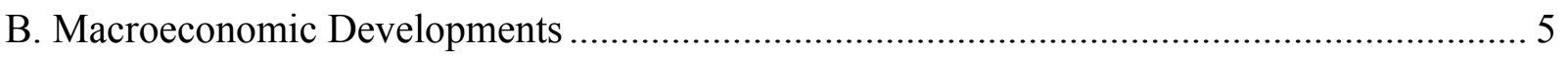

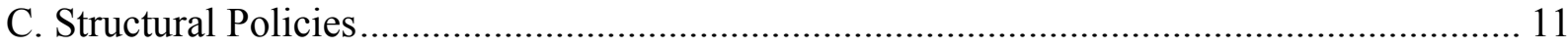

III. Assessment of the 2007 ECF-Supported Program..................................................... 13

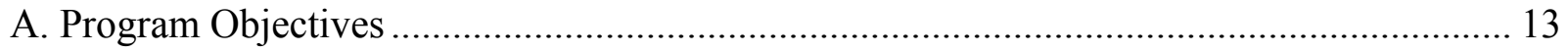

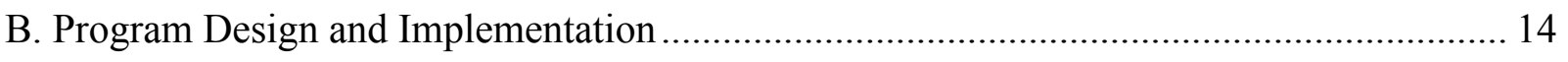

C. Program Performance ................................................................................................ 17

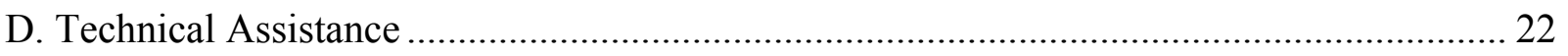

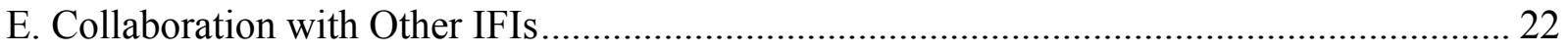

IV. Medium-Term Structural Policy Challenges ............................................................ 23

A. Stability and Growth: Half Full or Half Empty? ...................................................... 23

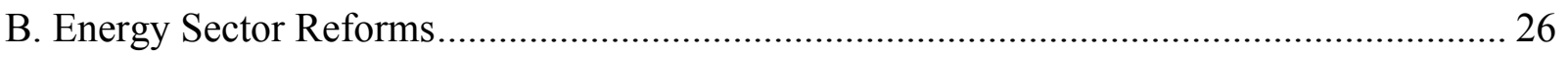

C. Fiscal Structural Reforms and Debt Management................................................... 27

D. Monetary and Financial Sector Reforms ............................................................... 30

E. Governance Reforms and Private Sector Development .............................................. 30

F. Poverty Reduction and Social Policy Reforms ........................................................ 31

\footnotetext{
${ }^{1}$ The team comprised M. Ayhan Kose (RES, head), Issouf Samake (WHD), Linda Kaltani (SPR), and Asmaa Adel ElGanainy (FAD), with support from Ezgi Ozturk (RES). The report benefited from extensive interviews with current and past members of the Fund, World Bank, and IDB teams working on Nicaragua.
} 


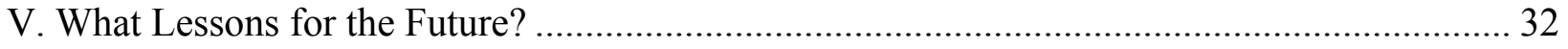

A. Summary Assessment and Lessons Learned............................................................ 32

B. Strategy for Future Fund Involvement .................................................................. 34

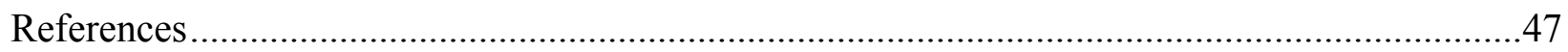

Table

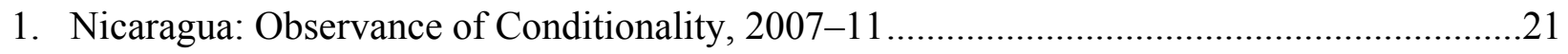

Figures

1. Selected Economic and Financial Indicators, 2002-11 f.................................................

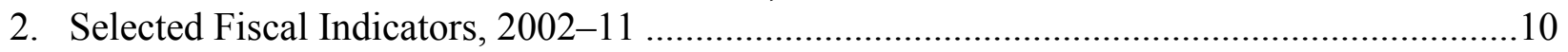

3. Program Performance-Selected Economic Indicators ...................................................19

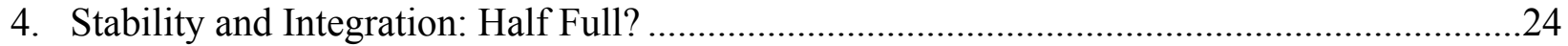

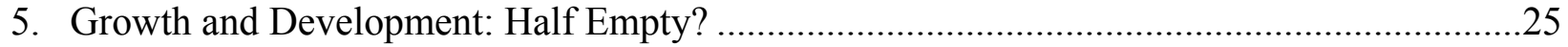

Boxes

1. How Did Nicaragua Cope With the Global Financial Crisis? .............................................6

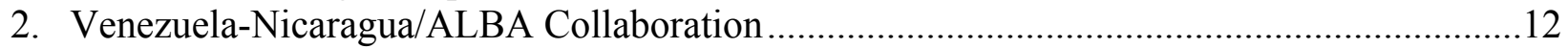

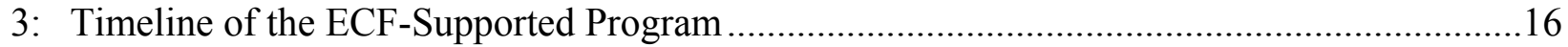

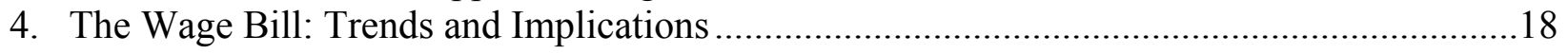

Appendices

I. Reflections of the 2007 EPA Recommendations on the 2007 ECF Program.......................37

II. Nicaragua: Major Events During the 2007-11 ECF Program ..............................................38

III. Nicaragua: ECF-Supported Program Structural Reform Agenda, 2007-11 .........................39

IV. Nicaragua: Millennium Development Goals ..............................................................41

Annexes

I. The Views of the Authorities .........................................................................................42

II. The Views of Other Stakeholders in Nicaragua ............................................................44

III. Statement of the Authorities .......................................................................................45 


\title{
Background
}

\section{EXECUTIVE SUMMARY}

The Nicaraguan economy was buffeted by a series of adverse shocks over the 2007-11 period. In addition to the global financial crisis, the period was marked by commodity price shocks, natural disasters, allegations of electoral fraud, and occasional frictions between the executive and legislative branches of the government. Social tensions and governance concerns undermined traditional donor support.

\section{The 2007-11 ECF-Supported Program: Design, Implementation and Outcomes}

The program followed closely the main recommendations of the 2007 EPA. The program sought to consolidate macroeconomic stability while creating the fiscal space for additional social spending in the context of debt sustainability. The structural reform agenda was carefully sequenced, with clear mediumterm objectives. The program was able to correctly identify key risks, many of which materialized.

\begin{abstract}
Although the program was flexible, the confluence of exogenous shocks and weak program ownership led to implementation challenges. There were multiple delays in the completion of reviews in the first three years of the program primarily because of shocks and policy slippages. Conditionality naturally evolved over time as the program flexibly adjusted to changes in the global environment. In the aftermath of the global financial crisis, safeguarding macroeconomic stability became the main priority, and the focus and objectives of the program were changed accordingly in late 2009. However, there were also instances when weak ownership resulted in the postponement of reviews and delays in meeting program targets. For example, the fourth review could not be completed on time because of fiscal slippages associated with the introduction of a monthly wage bonus that was not contemplated in the program.
\end{abstract}

The program played a major role in helping preserve macroeconomic stability, but progress in structural reforms was uneven. Despite the challenging environment, the program was effective in helping the Nicaraguan authorities design a realistic policy framework that resulted in a significant improvement in fiscal balances especially after the global financial crisis, and was instrumental in keeping inflation under control. Although it paved the way for the completion of some reforms involving tax policy and the energy sector, the program fell short of making progress in some key structural areas, such as pension and public financial management reforms.

\section{What is Next?}

Nicaragua faces formidable structural reform challenges. Nicaragua's growth performance has been weak over the past two decades partly because the patchy implementation of structural reforms has prevented the country from overcoming key impediments to growth: protracted challenges of the energy sector and pension system; weak institutions and governance; scarcity of human capital; poor infrastructure; underdeveloped financial markets; and low level of private sector development. Eliminating these impediments can improve long-term growth prospects, reduce poverty, and increase the resilience of the economy.
A successor Fund-supported program may help Nicaragua in many dimensions, but it would have to be backed by strong ownership. A program with the Fund would help Nicaragua maintain macroeconomic stability and make progress in reforms. It would also lend credibility to the authorities' policies, which, in turn, would help attract much needed FDI and other capital flows to the country. However, having strong program ownership is a critical priority for successful outcomes. The macroeconomic program should be flexible in incorporating the necessary mechanisms to cope with exogenous shocks, including the possibility of a sudden decline in Venezuela-related flows. The structural agenda needs to focus on a well-defined set of macro-critical areas with the highest pay-off in terms of Nicaragua's stability and growth priorities, key among these being the energy sector and the pension system. 


\section{INTRODUCTION}

1. This Ex-Post Assestment of Longer-Term Program Engagement (EPA) report reviews Nicaragua's performance under the 2007-11 program supported by an Extended Credit Facility (ECF) arrangement. ${ }^{2}$ The arrangement, which was set to be completed in September 2010, was extended twice in 2010 and expired in December 2011. ${ }^{3}$ The original access of SDR 71.5 million (55 percent of quota) was augmented to SDR 78 million at the time of the first review in 2008 to help Nicaragua cope with the impact of a hurricane and floods.

\section{Nicaragua has a long history of engagement with the Fund but has only recently} started to establish a track record of program completion. Since 1994, the country has had a Fund-supported program almost continuously. The two programs of the 1990s went off track because of setbacks in addressing policy slippages and undertaking reforms. The last two programs were completed despite multiple interruptions.

Nicaragua: Arrangements with the Fund, 1994-2011

(As of May 31, 2012)

\begin{tabular}{lccccc}
\hline Type & $\begin{array}{c}\text { Date of } \\
\text { Arrangement }\end{array}$ & $\begin{array}{c}\text { Expiration } \\
\text { Date }\end{array}$ & $\begin{array}{c}\text { Numb. of } \\
\text { reviews }\end{array}$ & $\begin{array}{c}\text { Amount Approved } \\
\text { (SDR Million) }\end{array}$ & $\begin{array}{c}\text { Amount Drawn } \\
\text { (SDR Million) }\end{array}$ \\
\hline$E C F^{2 / 3 /}$ & June 24, 1994 & June 23, 1997 & 0 & 120.12 & 20.02 \\
$E^{2 / 3 /}$ & Mar 18, 1998 & Mar 17, 2002 & 2 & 148.96 & 115.32 \\
$E^{2 /}$ & Dec 13, 2002 & Dec 12, 2006 & 11 & 97.50 & 97.50 \\
ECF $^{2 /}$ & Oct 05, 2007 & Dec 4, 2011 & 7 & 78.00 & 78.00 \\
\hline
\end{tabular}

Source: Survey and Arrangement Database, IMF Finance Department.

${ }^{1 /}$ Number of reviews completed.

${ }^{2 /}$ Formerly PRGF.

${ }^{3 /}$ Program off track (and not completed).

\section{Daunting development challenges of the Nicaraguan economy have often} complicated the design and implementation of Fund-supported programs. Nicaragua is the second poorest country in the Western Hemisphere (after Haiti). It is inherently prone to natural disasters and commodity price shocks. High levels of public debt, large current account deficits, volatile inflation, and high levels of dollarization have made the formulation of economic policies extremely challenging. Political and social tensions have often threatened macroeconomic stability and slowed down structural reforms.

\footnotetext{
${ }^{2}$ This is a full EPA report (instead of an update of the 2007 EPA) since the program under review was interrupted for more than six months (see Ex-Post Assessments of Members with a Longer-Term Program Engagement-Revised Guidance Note). The ECF was formerly called the Poverty Reduction and Growth Facility (PRGF).

${ }^{3}$ In September 2010, a two-month extension of the program was approved to allow for the completion of the fourth and fifth reviews. The second extension was for twelve months to help anchor policies through December 2011.
} 
4. The 2007 EPA reviewed the Fund-supported programs during the period 19942006. The EPA noted that successive Fund-supported programs had helped maintain broad macreconomic stability and lent credibility to the policy framework. However, progress on structural reforms had been slow, reflecting poor implementation, institutional weaknesses and difficulties in building consensus (Appendix I summarizes recommendations of the 2007 EPA).

5. The rest of the report is organized as follows. Section II presents a brief summary of macroeconomic and structural developments during 2007-11. Section III assesses the objectives, design and performance of the 2007 ECF-supported program. Section IV puts in perspective Nicaragua's progress during the past decade and identifies the main medium-term structural policy challenges that must be overcome to promote macroeconomic stability, and sustained growth and poverty reduction. The last section presents a summary of lessons and provides recommendations for future Fund engagement.

\section{A BIRD'S EYE VIEW OF ECONOMIC DEVELOPMENTS IN NICARAGUA: 2007-11}

\section{A. Background}

\section{Over the 2007-11 period, the Nicaraguan economy was buffeted by a series of} adverse shocks. In addition to the global financial crisis of 2008-09, the period was marked by commodity price shocks, natural disasters, allegations of electoral fraud, and occasional frictions between the executive and legislative branches of the government (see Appendix II for a list of major events during this period). The Sandinista government that took office in early 2007 did not have legislative majority, but was able to forge consensus for approval of few structural reforms in the Assembly. Social tensions and governance concerns weakened traditional donor support. President Ortega was re-elected for a second term in November 2011.

\section{B. Macroeconomic Developments}

7. Despite the challenging environment, economic conditions in Nicaragua remained relatively stable during 2007-11, except in the aftermath of the global financial crisis. Spillovers from the crisis together with domestic political turmoil hit the Nicaraguan economy hard in 2009 when output contracted by about 1.5 percent (Box 1). However, the economy rebounded quickly from the crisis. In recent years, key drivers of growth

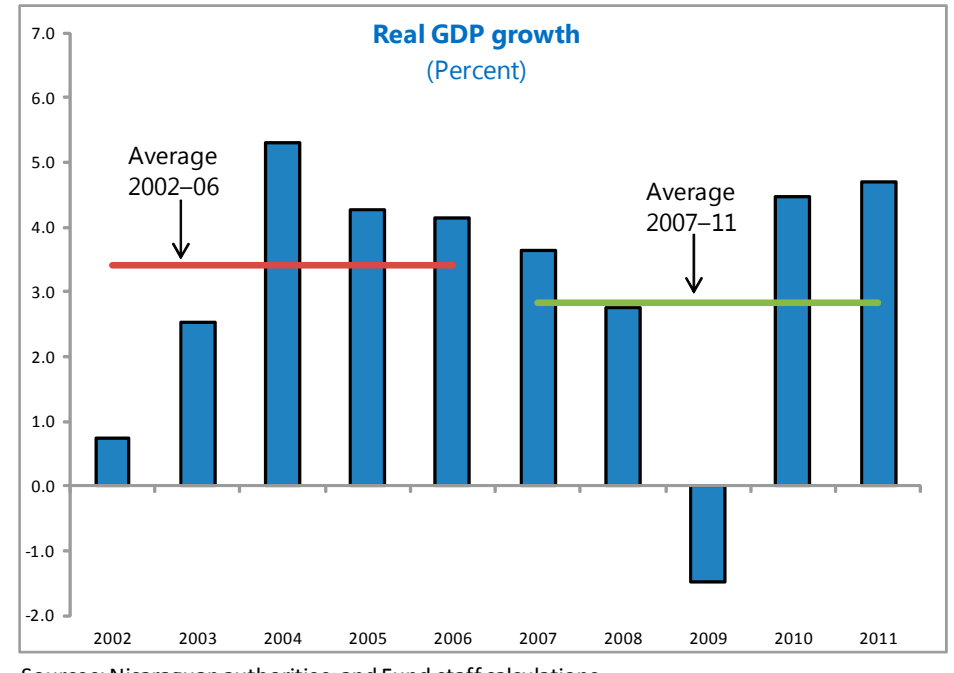

Sources: Nicaraguan authorities; and Fund staff calculations. 


\section{Box 1. How Did Nicaragua Cope With the Global Financial Crisis?}

Initial conditions. Nicaragua entered the global financial crisis with limited policy space despite the ECF-supported arrangement. Its chronically high current account deficit widened further as a result of the fuel and food price hike in 2008. The central government fiscal balance turned to a deficit in 2008 (-1.2 percent of GDP) from a surplus in 2007 ( 0.4 percent of GDP). Inflation and the public debt-to-GDP ratio were twice the regional averages. Allegations of fraud during the November 2008 municipal elections led to social unrest and a decline in budget support from traditional donors.

Impact of the crisis. The global crisis affected Nicaragua through multiple channels. The sharp contraction in global demand lowered Nicaragua's exports, and remittances declined by 5.7 percent. Owing to tight global financial conditions and governance concerns, both FDI and development assistance registered significant declines. Although the financial system remained stable, credit to the private sector declined, exacerbating the impact of external shocks on private investment and consumption.

\section{Policy response. Despite the limited} buffer, fiscal policy was accommodative during the crisis. Specifically, fiscal policy helped support domestic demand through higher current spending (mostly wage increases-up 9 percent in real terms-and pension and health insurance benefits-up 20 percent). The implied fiscal impulse, however, was the lowest in Central America. Although revenues were stable, the decline in grants along with the jump in expenditures increased the central
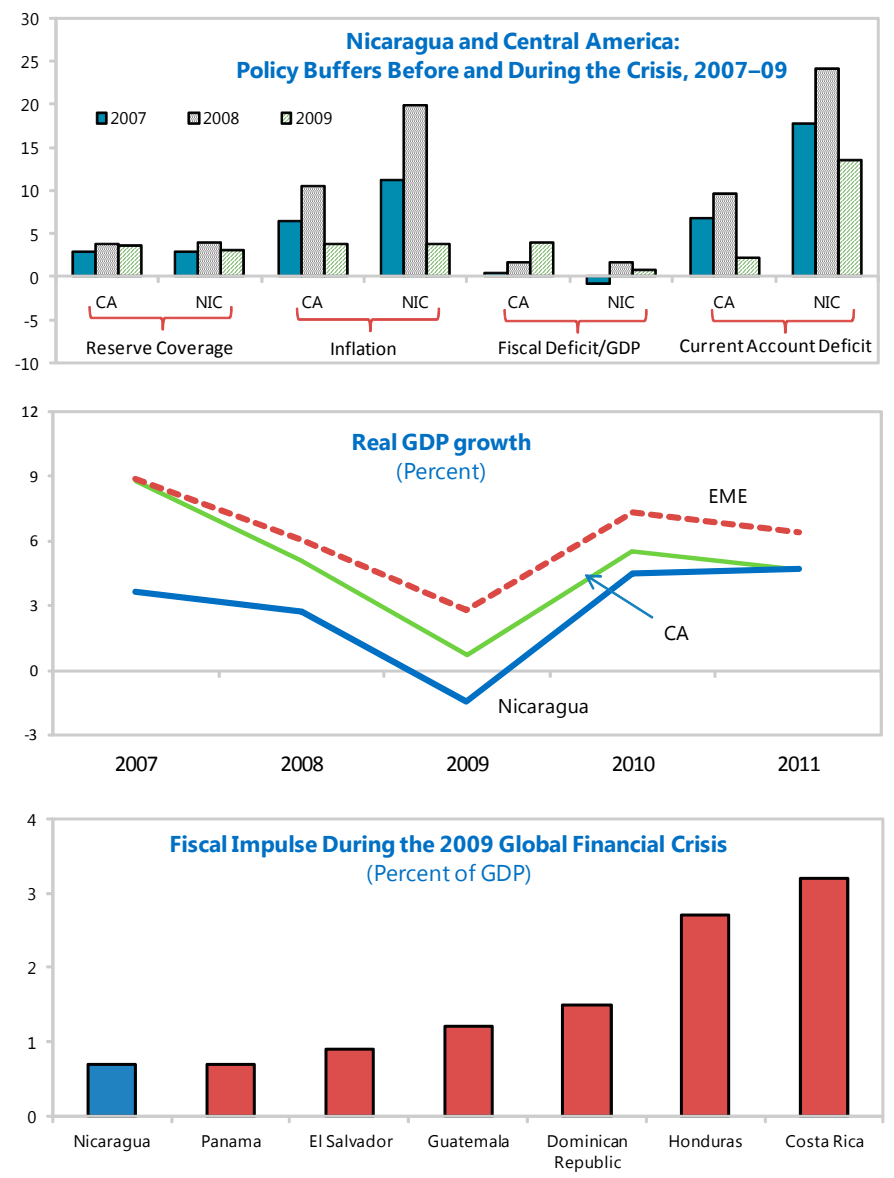

Sources: Nicaraguan Authorities; World Economic Outlook; and IMF staff calculations. Notes: CA: Average of Central American countries excluding Nicaragua. EME: Average of Emerging Market Economies. Fiscal deficit refers to consolidated public sector deficit. Reserve coverage is in months of imports. All other variables in the top panel are in percent of GDP. government deficit from 1.2 percent of GDP in 2008 to 2.8 percent in 2009 . The central bank adopted some supportive measures as well: it increased the size and flexibility of its credit lines in early 2009 and signed a one-year contingent credit line with the Central American Bank for Economic Integration (CABEI).

Program adaptation. The global financial crisis led to a significant change in the content and objectives of the Fund-supported program. Agreement on a program aimed at containing the fiscal gap and protecting the international reserves position took time to reach due to uncertainties regarding the impact of the crisis and the size of donor support, as well as political resistance to expenditure restraint. Prolonged negotiations led to the postponement of the second review. The combined second and third reviews were completed in November 2009 after the authorities committed to improving fiscal balances, undertaking a revenue-enhancing tax reform, and implementing measures to advance the structural reform agenda. In view of the sharp change in the external environment, the focus of the revised program shifted to safeguarding macroeconomic stability. 
have been commerce and manufacturing on the supply-side, and private consumption and investment on the demand-side (Figure 1).

8. Inflation spiked early in the program, but was kept broadly under control. Average annual headline inflation rose to 9.7 percent in 2007-11 from 7.3 percent in 2002-06 mainly due to the food and oil price upswings, and natural disaster-related shortages in the later period.

These inflation rates can be explained by the high pass-through from global commodity prices to headline inflation (partly reflecting a comparatively large share of food in the consumption basket). Nicaragua's crawling peg exchange rate regime was a moderating factor insofar as it provided a nominal anchor for monetary policy and set a floor on inflation expectations.

\section{External imbalances remained large despite a significant improvement in the} international reserve position. After reaching a decade-high of 25 percent of GDP in 2008 because of the escalation of oil prices, the external current account deficit followed a stable path during the past three years. The

growth in exports and remittances was generally offset by a persistently large bill of imports, especially oil bill. The current account deficit, however, has been more than financed by loans and FDI. Although there was a steady decline in official assistance owing to governance concerns, this was compensated by a sharp increase in financial assistance from Venezuela. Monetary

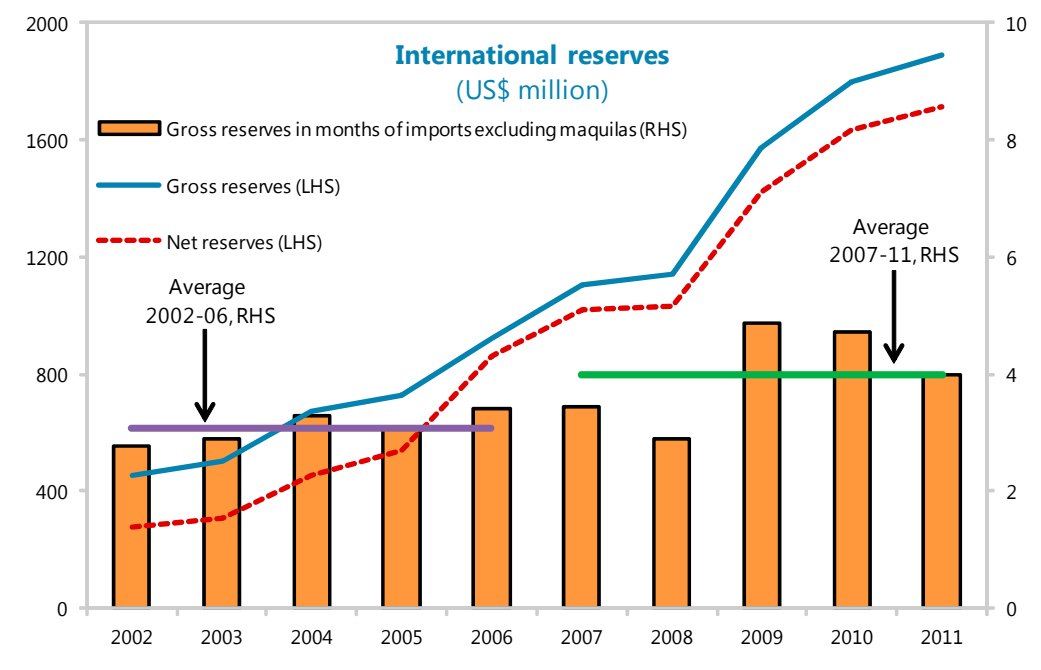

Sources: Nicaraguan authorities; and Fund staff calculations. policy aimed at protecting the reserve position and robust capital inflows accommodated a substantial increase in international reserves. Staff assessments of Nicaragua's external stability suggested no strong evidence of an exchange rate misalignment. ${ }^{4}$

10. The financial sector proved to be resilient. Following the suspension of debt service on public bonds during a legal investigation into alleged improprieties in the handling of the 200001 banking crisis, two major banks were affected, which increased financial uncertainty

\footnotetext{
${ }^{4}$ See Staff Reports for the 2010 Article IV and the Sixth Review under the ECF program (IMF Country Report No. 11/118).
} 
Figure 1. Nicaragua: Selected Economic and Financial Indicators, 2002-11 Growth is driven by consumption and investment. Inflation has been under control since 2008.

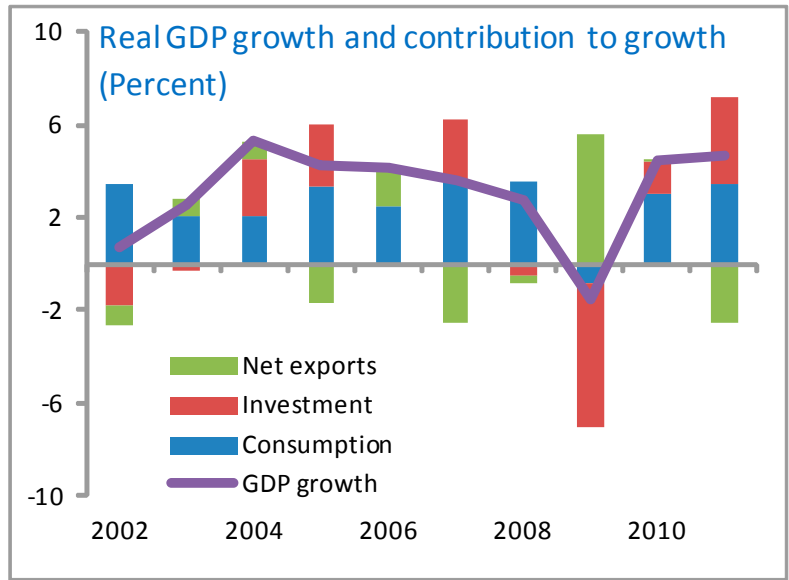

Unemployment has stabilized recently.

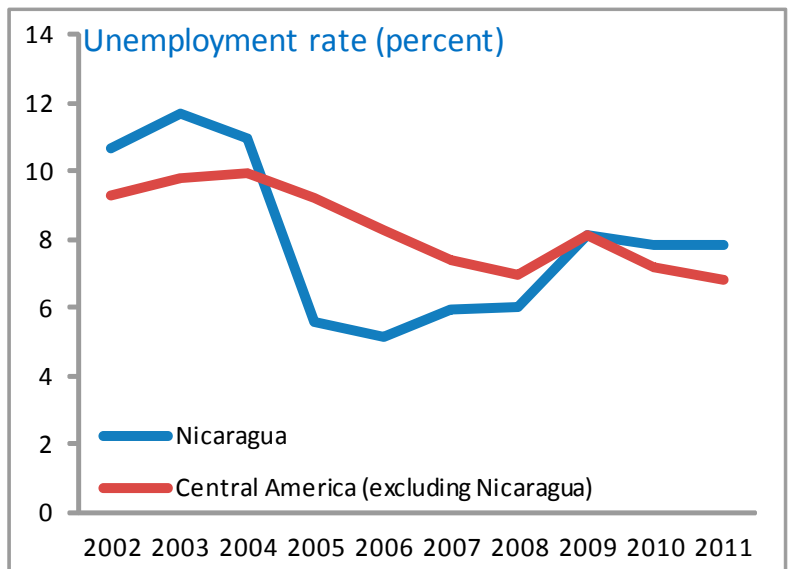

Credit has been recovering from the crisis.

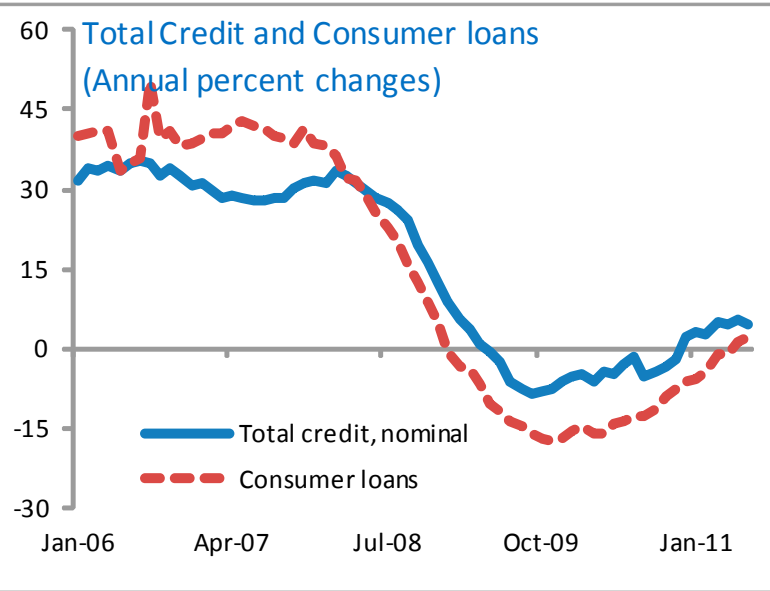

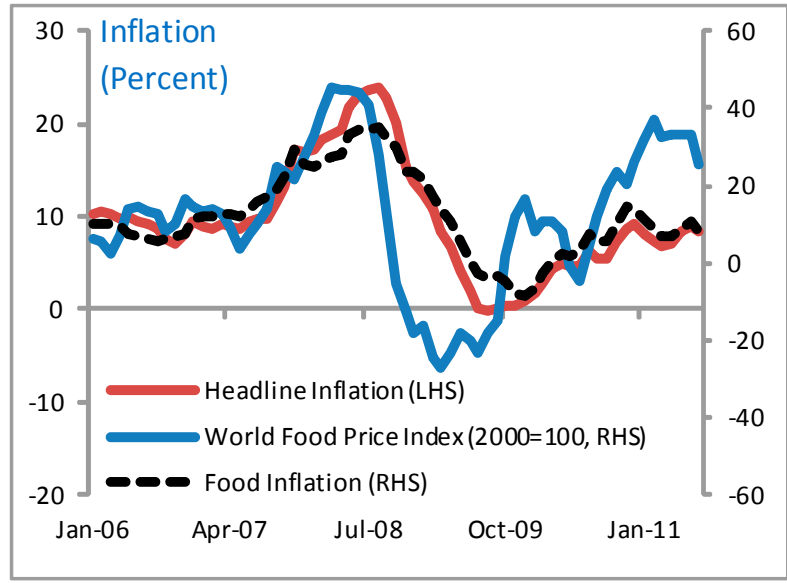

Current account deficit remains high.

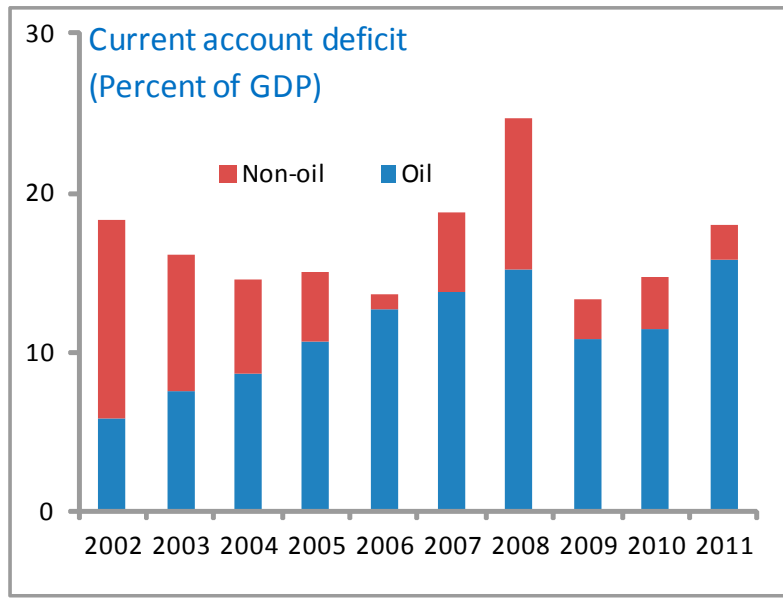

Deposits in foreign currency have been driving bank deposits.

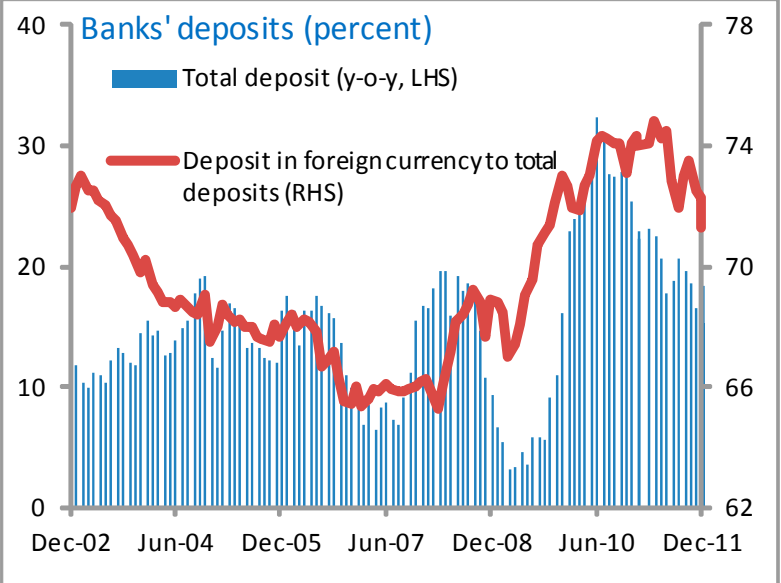

Sources: Nicaraguan authorities; and Fund staff calculations. 
during 2008. ${ }^{5}$ However, the speedy approval of a restructuring agreement between the central bank $(\mathrm{BCN})$ and the banks helped mitigate the effect of this event on the financial sector. The direct impact of the global financial crisis on the banking system was minimal nor was there a decline in bank deposits (which was already a major concern after the municipal elections in November 2008). Nicaraguan banks did not have exposures to toxic assets and they did not rely much on foreign credit lines before the 2009 crisis. However, as uncertainty increased, banks retrenched credit to the private sector in order to build liquidity buffers. Non-performing loans (NPLs) increased and banks' profitability declined in 2009. As growth picked up in 2010, credit provision accelerated, the share of NPLs declined, and banks' profitability started to improve, while deposits in local and foreign currency rose.

\begin{tabular}{|c|c|c|c|c|c|c|c|}
\hline \multicolumn{8}{|c|}{$\begin{array}{l}\text { Nicaragua: Financial Soundness Indicators, 2005-11 } \\
\text { (In percent, unless otherwise indicated) }\end{array}$} \\
\hline & 2005 & 2006 & 2007 & 2008 & 2009 & 2010 & 2011 \\
\hline \multicolumn{8}{|l|}{ Capital adequacy } \\
\hline Regulatory capital to risk-weighted assets & 13.6 & 14.5 & 14.1 & 15.3 & 16.5 & 16.6 & 14.8 \\
\hline Regulatory Tier 1 capital to risk-weighted assets ${ }^{1 /}$ & 13.8 & 9.0 & 8.7 & 9.0 & 10.9 & 11.1 & 9.2 \\
\hline \multicolumn{8}{|l|}{ Asset quality } \\
\hline Nonperforming loans to total gross loans & 2.1 & 2.0 & 2.5 & 3.0 & 3.3 & 3.0 & 2.2 \\
\hline Nonperforming loans to total gross loans ${ }^{2 /}$ & 7.2 & 6.2 & 5.2 & 6.7 & 10.9 & 8.0 & 5.9 \\
\hline \multicolumn{8}{|l|}{ Earnings and profitability } \\
\hline Return on assets & 2.6 & 2.4 & 2.2 & 1.8 & 0.5 & 1.0 & 1.6 \\
\hline Return on equity & 29.7 & 25.1 & 22.5 & 18.1 & 4.8 & 10.8 & 16.7 \\
\hline
\end{tabular}

\section{Fiscal performance worsened following the global crisis, but has strengthened since} then (Figure 2). In the aftermath of the Lehman shock, fiscal policy focused on supporting domestic demand as the authorities attempted to soften the impact of the crisis. The growth in current spending along with shortfalls in grants led to a significant jump in the central government deficit in 2009. Revenue performance has improved following the tax reform of 2009. The composition of public spending has deteriorated, however, with a slight increase in the share of current expenditures over the past five years. ${ }^{6}$ The public debt-to-GDP ratio registered a small decline over 2007-11, but remained high at about 73 percent of GDP.

\footnotetext{
${ }^{5}$ During a banking crisis in the early 2000 s, the Nicaraguan central bank issued roughly US\$400 million (about 10 percent of GDP) in bank bonds (Certificados Negociables de Inversion, CENIs) to cover the difference between performing assets and liabilities of insolvent banks that were intervened and absorbed by other private banks. These bonds were held by two large privately owned local banks, which together accounted for close to 60 percent of total banking system deposits, and represented an important share of their capital and assets.

${ }^{6}$ The initial increase in current expenditures in 2006-07 was due to a reclassification of some expenditure items from investment to current spending in 2007.
} 
Figure 2. Nicaragua: Selected Fiscal Indicators, 2002-11

Central government revenue collection has improved over time...

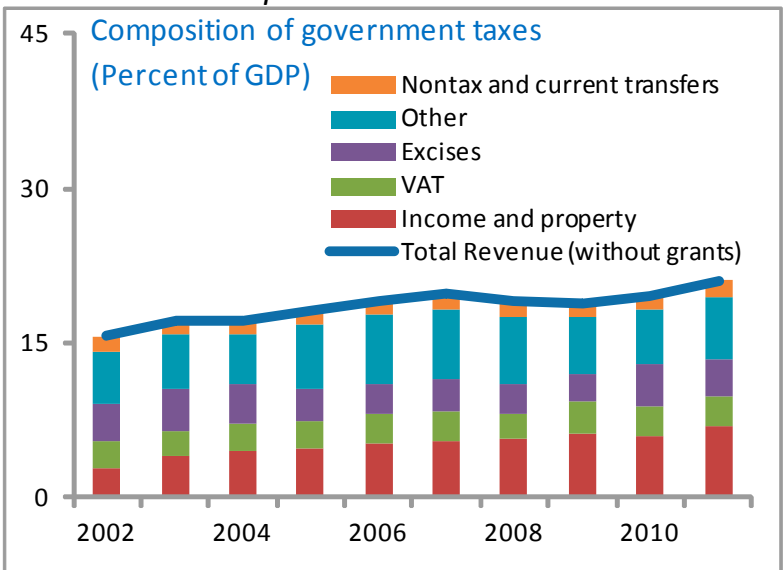

Hence, the overall public sector balance has also improved.

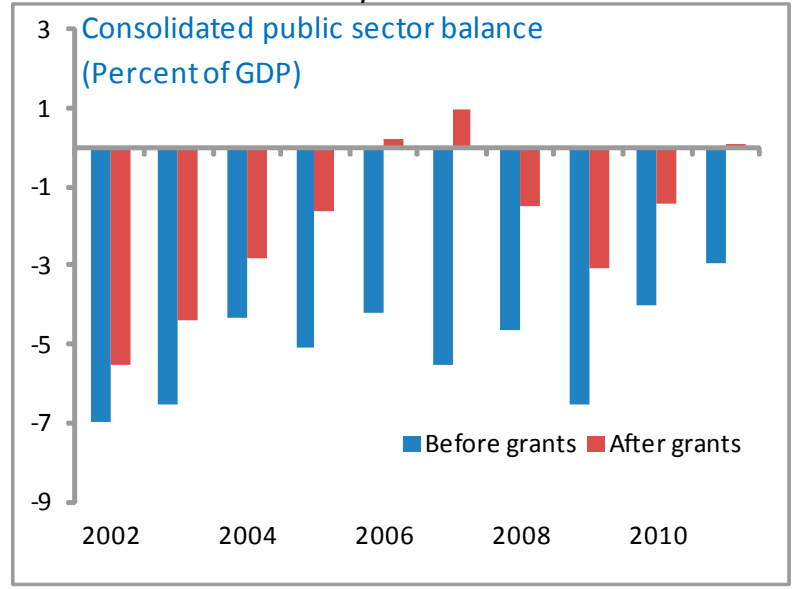

... the composition of the central government expenditure has deteriorated, ...

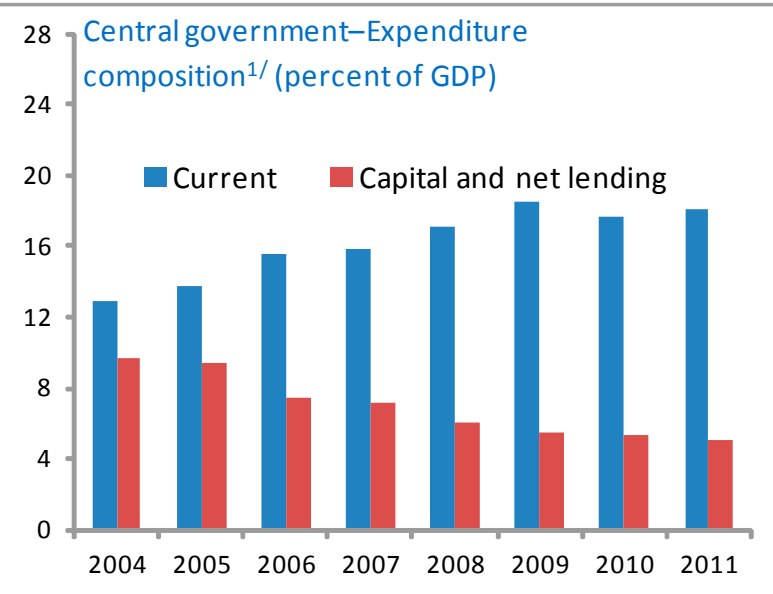

... resulting in strongerfiscal performance in 2010-11.

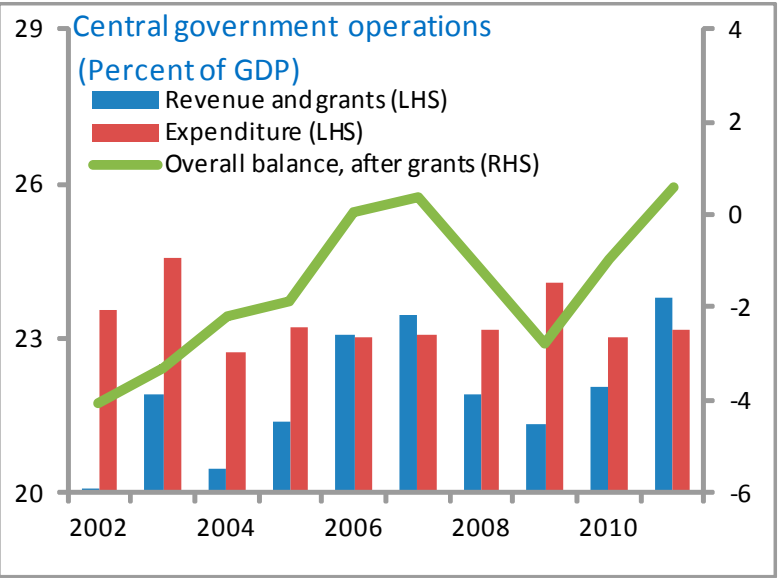

But, the deficit of public entreprises is increasing, ...

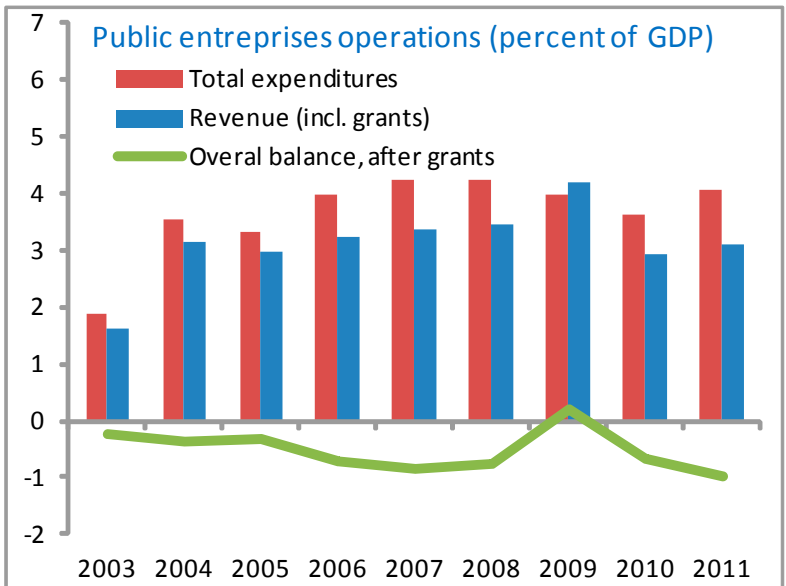

... and, despite HIPC debt relief, public debt remains high.

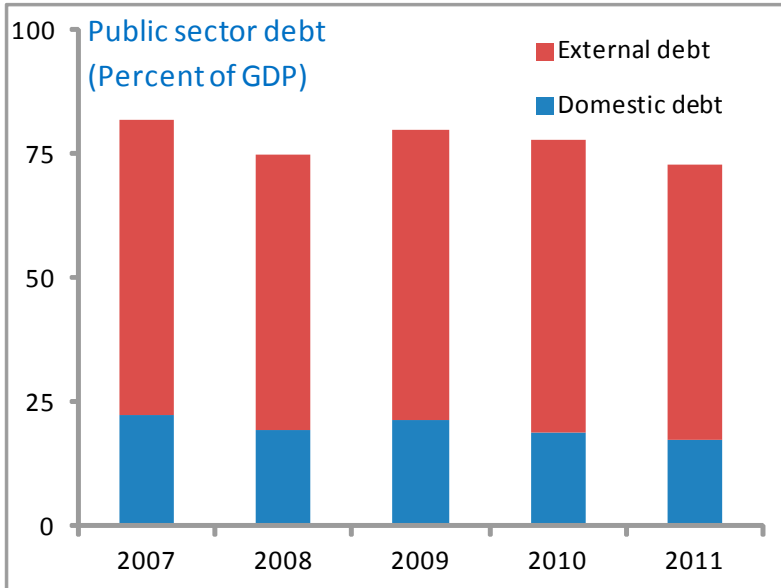

Sources: Nicaraguan authorities; and Fund staff calculations.

${ }^{1 / C}$ Current expenditure includes wages and salaries, interest on central government debt, goods and services, and transfers and subsidies. 


\section{Structural Policies}

12. The approval of a tax reform in 2009 was a major achievement, but progress on other fiscal reforms was mixed. The reform aimed at broadening the tax base by rationalizing tax incentives and simplifying the tax structure, while increasing the progressivity of the system. Its adoption contributed to an increase in revenue intake in the last two years of the program. Nicaragua's strong revenue performance is evident in its high 10 tax-to-GDP ratio relative to regional peers. Some revenue administration reforms were also implemented. However, progress on public financial management (PFM) has been quite limited.

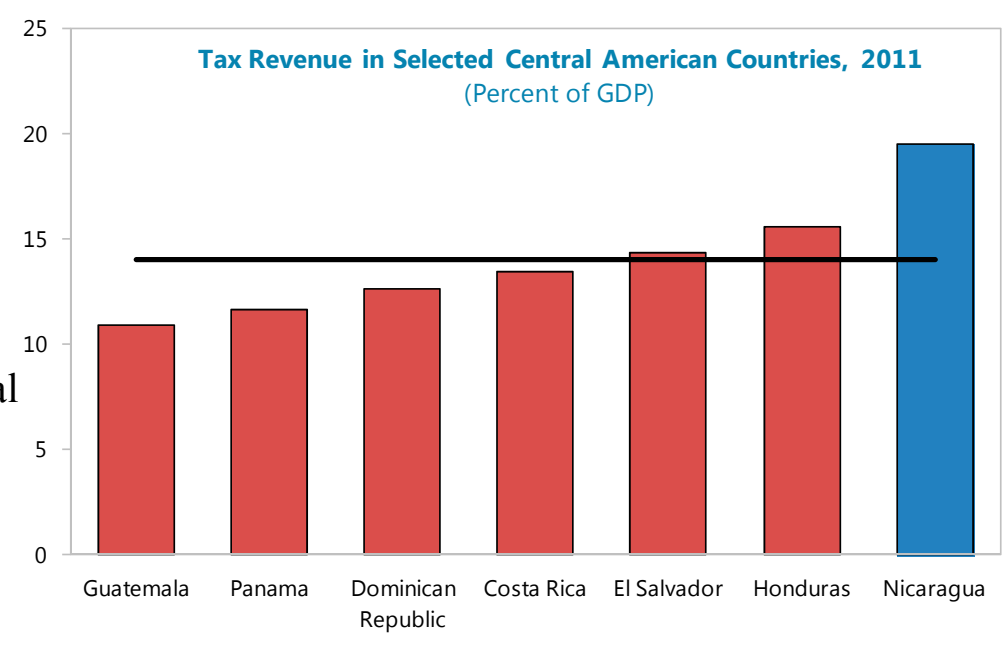

\section{There were improvements in the central bank's legal framework and financial} sector supervision. The central bank charter was modified in 2010 to improve its governance structure and political autonomy. Coordination between the $\mathrm{BCN}$ and the Ministry of Finance also improved. Key reforms in the area of financial sector supervision included: (i) the approval of a regulatory framework for the micro-finance institutions (MFIs) with the aim of strengthening supervision, transparency, and efficiency of the sector (in June 2011); (ii) improvements in the monitoring and supervision of financial cooperatives by the oversight agency (INFOCOOP, in June 2011); (iii) the adoption of a minimum liquidity requirement and introduction of capital requirement to enhance bank regulation and oversight (in March 2011); and (iv) stress testing on a pilot basis (in December 2011) and continued implementation of (onsite) banking supervision.

\section{A series of reforms were undertaken to strengthen the financial position and} regulatory framework of the electricity sector and to address power shortages. The electricity sector was in a dismal state in 2006; electricity shortages were frequent and unpredictable owing to insufficient electricity generation, large distribution losses, and weaknesses in the legal framework to combat electricity theft. In 2008, under the ECF-supported arrangement, the government and the privately-owned distribution company agreed on a new Electricity Sector Protocol to strengthen the sector's finances. The protocol was further strengthened by the approval of a law imposing sanctions for electricity theft. These changes led to a reduction in unbilled electricity by the distribution company from 27 percent of total usage in 2006 to about 20 percent in 2010 . In addition, electricity generation capacity was increased from $760 \mathrm{MW}$ in 2006 to $1,110 \mathrm{MW}$ in 2010, which helped eliminate daily blackouts.

15. Transparency of foreign aid flows increased. In 2007, Nicaragua started receiving a substantial amount of official assistance under the Alternativa Bolivariana de las Americas (ALBA) cooperation agreement with Venezuela (Box 2). The Venezuela-related gross flows 


\section{Box 2. Venezuela-Nicaragua/ALBA Collaboration}

What is the collaboration about? The collaboration is primarily linked to oil imports and oil-related financing, but it also involves: (i) FDI through a bi-national firm, ALBANISA (51 percent owned by Venezuela's state-oil company PDVSA and 49 percent by Nicaragua's state-oil company PETRONIC); (ii) private sector financing (including through Venezuela's development bank, BANDES); and (iii) the provision of grants for budgetary support.

How does it work? It involves both public and private institutions, including a financial credit cooperative that directs a part of the funds from the oil collaboration toward social spending. In a nutshell, the scheme works as follows: (i) ALBANISA pays 100 percent of the oil bill on commercial terms 90 days after the bill of landing; (ii) 50 percent of this payment is received by PDVSA and the remaining 50 percent is transferred, on behalf of PDVSA, to the private financial credit cooperative Caja Rural Nacional (CARUNA) in the form of long-term concessional loans (payable over 25 years, with a 2-year grace period, at an interest rate of 2 percent); (iii) CARUNA uses 40 percent of the funds to provide financing to both the private and the public sectors (e.g., subsidies and transfers, wage bonuses, and lending to small rural cooperatives); (iv) it sends the remaining 60 percent to a Trust Fund owned by PDVSA but managed by CARUNA that can only be used for purposes and financing terms approved by Venezuela.

Why is transparency of the Venezuela-related flows so important? Because they are sizeable, these flows have wide-ranging implications for macroeconomic and financial stability, and governance:

- $\quad$ Fiscal balances. The funds have helped to pay for transfers and subsidies for transportation and energy, and, since 2010, public sector wage bonuses. The practice of paying for recurrent fiscal spending with transitory resources is a clear risk for fiscal stability. In addition, the off-budget nature of such spending undermines fiscal transparency and risks complicating wage negotiations in the private sector.

- $\quad$ Debt sustainability. Having access to a sizeable, long-term, and concessional loan arrangement is a boon to a highly indebted country like Nicaragua. According to the Nicaraguan authorities, the Venezuelan assistance does not entail the contracting of direct and/or contingent public debt since CARUNA is the only institution liable for the long-term financing disbursed under the framework. That said, in the event of an adverse shock to CARUNA's finances, the possibility of its liabilities to be taken on by the government could be a risk to public debt sustainability. Given that a significant fraction (about 45 percent) of private external debt is now ALBA-related, a change in the concessional nature of ALBA loans could also increase Nicaragua's debt vulnerabilities.

- $\quad$ Balance of payments considerations. Venezuela related FDI flows are helping to narrow the external funding gap, but a sudden stop in these flows could have implications for the stability of the balance of payments (as evident by their size, see text table on the next page). A mitigating factor, however, is that large Venezuela-related deposits at commercial banks could serve to smooth the adjustment to such a shock.

- $\quad$ Financial stability. Deposits of ALBANISA and CARUNA at commercial banks reached 13 percent of total deposits in 2011 from almost zero in 2007. These deposits increase the available liquidity in the financial system, but they are concentrated in a few large banks. Although these banks hold substantial liquidity buffers, there can be risks stemming from excessive concentration of the sizeable flows to the financial stability.

- $\quad$ Governance. The aid flows from Venezuela finance many social programs. However, a substantial portion of the aid flows goes through the private sector, creating monitoring challenges and risks for their effectiveness, as they fall outside the purview of the Comptroller General. The flows allowed the authorities to keep electricity tariffs unchanged in 2011 despite rising world oil prices, thus severing the link between tariffs and generation costs. This undermined the general principle of targeting subsidies as much as possible to vulnerable segments of the society. 
increased from 3 percent of GDP in 2007 to 7.6 percent in 2011. Monitoring of these large flows became increasingly important for the economic program given their wide-ranging implications for economic stability and governance (because of their distribution through public and private channels). The program's requirement of the publication of biannual reports documenting sources and uses of all foreign aid flows, including details on flows from Venezuela (towards the end of the program), helped improve their transparency and monitoring.

\begin{tabular}{|c|c|c|c|c|c|c|}
\hline & $\frac{2007-11}{\text { Cumulative }^{1 /}}$ & 2007 & 2008 & 2009 & 2010 & 2011 \\
\hline & \multicolumn{6}{|c|}{ Million of US\$ } \\
\hline Total & 2,143 & 168 & 459 & 441 & 520 & 555 \\
\hline Oil collaboration ${ }^{2 \prime}$ & 1,458 & 69 & 293 & 235 & 324 & 536 \\
\hline FDI & 380 & 46 & 131 & 147 & 11 & 45 \\
\hline \multirow[t]{2}{*}{ Others (net, including amortization) $)^{3 /}$} & 305 & 52 & 35 & 59 & 185 & -26 \\
\hline & \multicolumn{6}{|c|}{ Percent of GDP } \\
\hline Total & 29.4 & 3.0 & 7.2 & 7.1 & 7.9 & 7.6 \\
\hline Oil collaboration ${ }^{2 \prime}$ & 20.0 & 1.2 & 4.6 & 3.8 & 4.9 & 7.3 \\
\hline FDI & 5.2 & 0.8 & 2.1 & 2.4 & 0.2 & 0.6 \\
\hline Others (net, including amortization) $)^{3 /}$ & 4.2 & 0.9 & 0.5 & 0.9 & 2.8 & -0.4 \\
\hline
\end{tabular}

Sources: Nicaraguan Authorities; and Fund staff calculations.

${ }^{1 /}$ Cumulative numbers in the lower panel are in percent of GDP in 2011.

${ }^{2 /}$ A portion of ALBA-related flows was used to finance off-budget transport subsidies and wage bonus in 2010 and 2011.

${ }^{3 /}$ Others include (i) bilateral cooperation with Venezuala; (ii) official transfers; (iii) private capital transfers; and (iv) net trade credits and short term loans. The 2010 figure includes a bilateral loan of US\$185 million to ALBA-CARUNA provided under different terms than the oil collaboration, i.e., 5 years maturity, 1 year grace and 2 percent interest.

16. Poverty incidence decreased and income inequality improved. Measures of income and consumption inequality declined from 2005 to 2009 while other key social indicators (including illiteracy rate, enrollment rate in primary education, drinking water and sewerage coverage in rural areas) improved. These favorable outcomes appeared to be a result of the relatively stable economic growth (except in 2009), increased demand for agricultural exports, and the government's social policies.

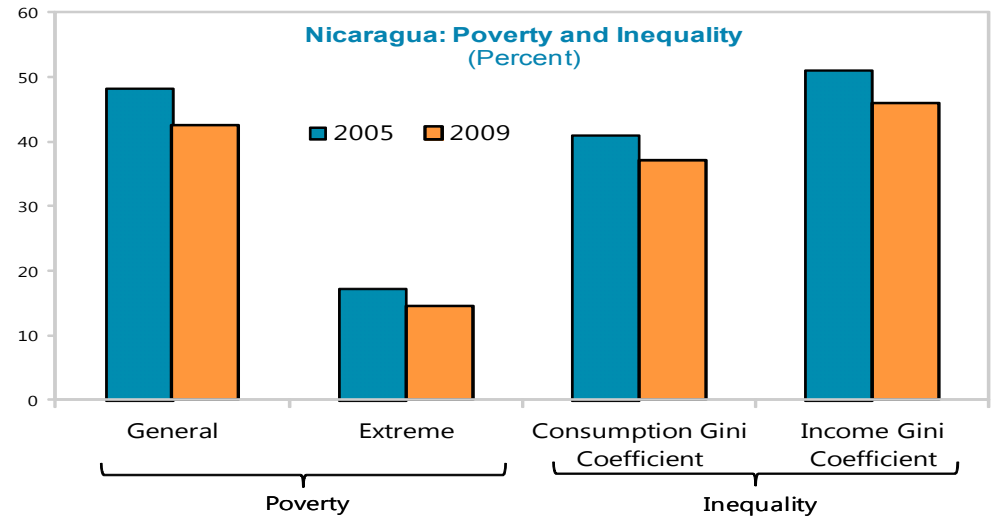

Sources: 2011 PRSP Update.

Note: General poverty indicates the percent of people below the poverty line, whereas extreme poverty indicates the percent of people below the extreme poverty line.

\section{ASSESSMENT OF THE 2007 ECF-SuPPORTED Program}

\section{A. Program Objectives}

17. The objectives of the ECF-supported program approved in October 2007 were in line with the main recommendations of the 2007 EPA. Mindful of implementation failures in past programs, the EPA had recommended focusing on removing impediments to long-term growth and poverty reduction while designing reforms that were carefully sequenced taking into consideration capacity constraints (see Appendix I). Having as a backdrop a generally stable 
external environment, the program approved in October 2007 sought to consolidate macroeconomic stability and reduce key vulnerabilities, while creating the fiscal space for additional social spending in the context of debt sustainability. Specifically, the program envisaged a gradual decline in public debt and the current account deficit, and a further accumulation of reserves.

18. The program set out a comprehensive approach to implement a number of key structural reforms in the energy, fiscal and financial sectors. In the energy area, the program aimed at improving electricity service and strengthening the finances of the sector to promote growth, enhance competitiveness, and reduce quasi-fiscal risks. In the area of fiscal reform, the objectives were to improve PFM practices and restore the sustainability of the pension system. The program also included measures aimed at improving transparency, and strengthening the finances of the central bank as well as its independence and accountability (see Appendix III for details of structural conditionality).

19. The program intended to build broad-based ownership, which, according to the 2007 EPA, had been inadequate in past programs. In order to enhance program ownership, the government's 2007 Economic and Financial Program served as the basis for the design of the Fund-supported program. In addition, staff undertook a consultation process with social and civic organizations at the early stages of program discussions to improve transparency and ownership by society as a whole.

\section{B. Program Design and Implementation}

20. The reform agenda focused on clear medium-term objectives in light of the lessons of the 2007 EPA. For instance, in the energy area, early actions aimed at strengthening the finances of the sector by establishing criminal penalties to discourage fraud in the consumption of electricity, and left the adjustment of tariffs for a later time. The design of the program incorporated the priorities of the authorities' Poverty Reduction and Strategy Paper (PRSP) on the social agenda by incorporating quantitative conditionality tracking poverty-related spending as well as structural conditionality monitoring social outcomes. The program design also stressed the need to facilitate access to credit to SMEs and the rural sector. ${ }^{7}$ In addition, the program correctly identified key risks, many of which materialized.

\section{The structural reform agenda was sequenced considering potential implementation} constraints. The first year of the program (2007-08) emphasized energy policy measures. The second year of the program (2008-09) envisaged the strengthening of PFM practices; while the third year (2009-10) contemplated specific steps to address medium-term challenges, including the under-funded social security system.

\footnotetext{
${ }^{7}$ In particular, the authorities' MEFP of October 2007 indicated that they planned to consolidate existing small state financial institutions and programs, and create a second-tier development bank (i.e., that would not take deposits from the public) to help increase credit to SMEs and the rural sector. In 2007, the authorities created, by law, a development bank (Banco Produzcamos), which became operational in early 2010. Moreover, the program was instrumental in reforming of microfinance institutions that provide credit to SMEs and the rural sector (the program included structural conditionality on this reform).
} 
22. Quantitative conditionality was streamlined when compared to the previous Fundsupported programs with Nicaragua. Quantitative targets at the outset focused on public finances and monetary policy. They encompassed the public sector overall balance, net domestic assets, net international reserves, limits on non-concessional external debt, and non-accumulation of external arrears of the public sector. The program initially did not include performance criteria on wages or electricity tariffs, which had been important elements of some of the previous programs.

23. The program was flexible despite multiple delays in the completion of reviews. Policy slippages and a variety of domestic and external shocks, especially the global financial crisis, led to delays in the completion of the first five reviews (Box 3). However, staff and the authorities were able to develop solutions to re-activate the program. For instance, they agreed on a satisfactory policy response after identifying the potentially damaging impact of the suspension of the debt service on public bonds, which led to the postponement of the first review (originally scheduled for March 2008).

24. The global financial crisis delayed the completion of the second review. Although Nicaragua had entered the global financial crisis with limited policy space (Box 1), the budget approved in early 2009 underestimated the impact of the crisis on growth and fiscal balances, and continued to feature large increases in current spending. The decline in budget-support loans and grants by donors, including the World Bank, and sharp declines in government revenues gave rise to a large ex-ante financing gap. By the time the consequences of the crisis on government revenues and activity became more evident to the authorities, the scope for containing the fiscal imbalance in 2009 was increasingly limited and some of the needed fiscal consolidation was shifted to 2010.

\section{The completion of the second and third reviews in November 2009 marked a} turning point in the program. The global financial crisis along with lower donor support threatened macroeconomic stability and made program financing a critical challenge. Preserving macroeconomic stability thus became the main policy priority, and the focus and objectives of the program were changed accordingly. Specifically, the program's main focus became maintaining macroeconomic stability and building a track record, and scope of the structural reform agenda was streamlined somewhat.

\section{The fourth review was} another marker in the evolution of the program. The fourth review could not be completed in May 2010 as envisaged owing to the government's decision to grant a wage bonus to public sector employees that was not contemplated in the program. The authorities argued that since the

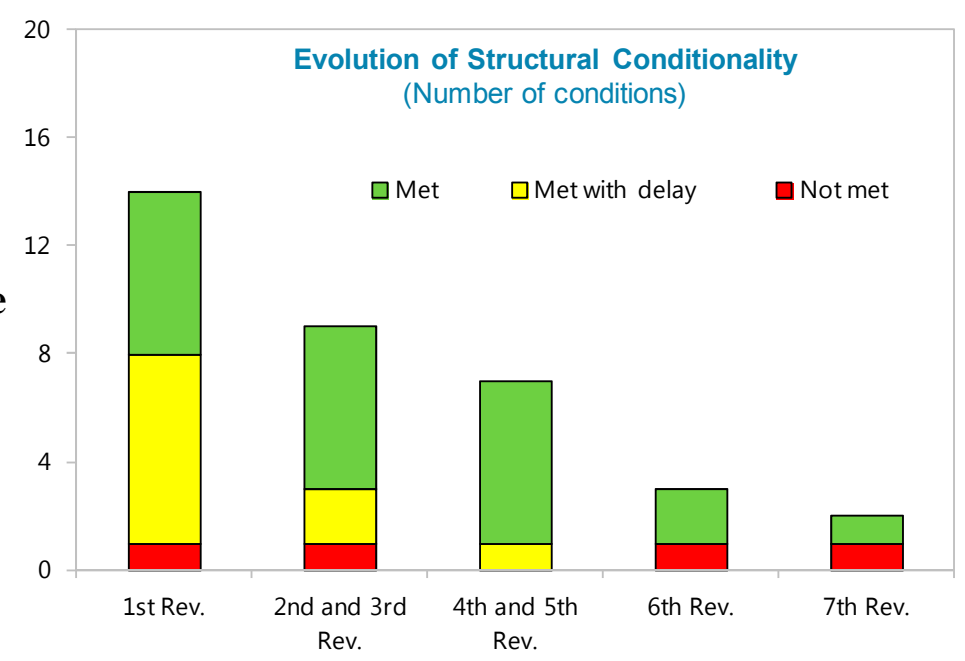




\section{Box 3. Timeline of the ECF-Supported Program}

\section{Like previous Fund-supported programs with Nicaragua, the 2007 program experienced multiple} delays. Specifically, the first five reviews under the arrangement were delayed because of policy slippages and a number of shocks (see Appendix III). The program was flexible in addressing the sources of these delays. For example, safeguarding macroeconomic stability became the main priority during the global financial crisis and the focus and objectives of the program were changed accordingly in late 2009.

- $\quad$ The first review was delayed following the suspension of service on public bonds in April 2008. The review was completed (six months after the original schedule) after restructuring agreements were reached, a bond swap was implemented, and the fiscal framework was reformulated. In addition, the disbursements under the program were augmented to help Nicaragua cope with the impact of natural disasters.

- The second review was delayed following setbacks in the adoption of a program necessary to contain the fiscal deficit and protect the international reserves position during the crisis year. Uncertainties regarding the impact of the crisis and the size of donor support following the municipal elections of late 2008, as well as delays in adopting corrective fiscal measures, further prolonged the program negotiations. The combined second and third reviews were completed in late 2009 when agreement was reached on the revised fiscal program and the structural agenda. The completion of the second and third reviews was a major turning point because the focus of the program clearly shifted towards maintaining macroeconomic stability.

- $\quad$ The fourth review could not be completed on time because of fiscal slippages associated with the introduction of a monthly wage bonus financed with grants from Venezuela. The wage bonus introduced additional risks to the fiscal consolidation objectives. After the program went off track, the fiscal program was revised and conditionality was strengthened, with the introduction of an indicative ceiling on the wage bill. The program was extended twice and access was rephased.

The sixth and seventh reviews were completed on time. These reviews focused on supporting the recovery after the global financial crisis and completing a small number of structural reforms.

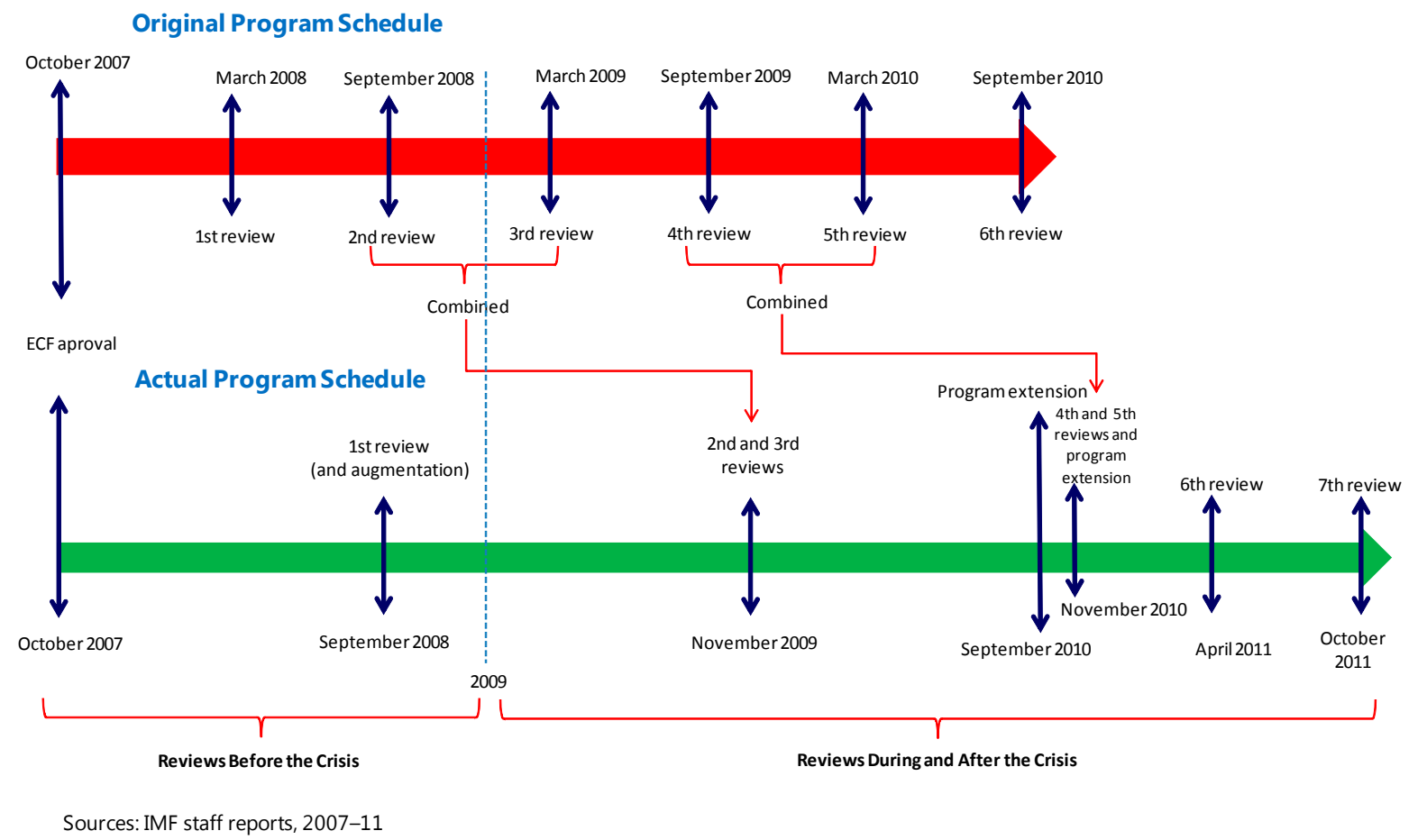


wage bonus was financed with grants from Venezuela, it did not have implications for the budget. However, staff correctly recognized the potentially adverse implications of the wage bonus for fiscal balances (Box 4). In the subsequent negotiations, staff proposed the introduction of an indicative ceiling on the wage bill. In addition, the macroeconomic program was revised to include measures to offset the fiscal effect of the wage bonus. The program was extended twice to have enough time for the completion of the combined fourth and fifth reviews and to help anchor policies through December 2011.

27. Uncertainties surrounding the size and uses of flows associated with the Venezuela/ALBA collaboration remained a major issue in program discussions. Starting with the first review, staff emphasized that all aid had to be subject to the same reporting standards, and structural conditionality focused on enhancing monitoring and transparency of official aid flows. However, significant progress in this area was achieved only at the time of the combined fourth and fifth reviews, which included a new structural benchmark on the publication of "Aid Reports" documenting the use, by economic sector, of all aid flows, including those from Venezuela. These reports showed that only part of the Venezuelan aid had been spent with the rest of the funds being deposited at a few commercial banks. Subsequently, the authorities also started providing aggregate data on bank deposits that allowed staff to broadly track those associated with the aid flows.

\section{Program Performance}

28. Significant gaps between some of the program projections and outturns, especially in the first three years, largely reflected the gravity of the shocks that hit the economy. Growth projections could not have foreseen the depth of the 2009 global crisis, but they also were too conservative in 2010 regarding the speed of the recovery (Figure 3 ). The rate of inflation fluctuated with global commodity prices and outturns in the first half of the program differed from projections. The public sector balance projections were pessimistic in light of stronger-than-expected tax revenues, especially in the last two years of the program. Net capital flows were often higher than envisaged, keeping international reserve levels above projections during most of the program period. The gaps between projections and outturns shrank during the sixth and seventh reviews owing to a relatively calmer global environment.

29. Although financing needs became a major concern especially in the aftermath of the global financial crisis, external financing constraints were not binding. At the time of the completion of the first review in September 2008, access under the program was augmented (by SDR 6.5 million) to help Nicaragua cope with the impact of natural disasters in 2008. Nicaragua received no budget-support loans from the World Bank after 2008. Budget-support grants from bilateral donors were also suspended during the last two years of the program owing to alleged shortcomings in electoral transparency. These developments and the global financial crisis led to a significant change in the sources of official external financing in 2009. The size and phasing of 


\section{Box 4. The Wage Bill: Trends and Implications}

How large is it? The public wage bill is quite large in Nicaragua. It is by far the largest single budgetary item, absorbing, on average, about one-third of the annual budget during 2006-11. Moreover, its share has been increasing over time, reaching 35 percent of total spending in 2011, compared to 32 percent in 2006.

Why did wage policies matter for the program? Wage policies were a key source of uncertainty surrounding expenditure plans during the program. Specifically, public sector wages were subject to unexpected large increases driven by political and social pressures. These increases in turn led to limited fiscal flexibility, reduced fiscal space for capital and social spending, and undermined the program's objective of fiscal consolidation. The first large increase in the wage bill occurred in 2007 on account of reclassification of expenditure items on health and education from investment spending to wages. In June 2007, the Assembly approved a law requiring bi-annual adjustments in the minimum wage, with a floor on wage increases equivalent to accumulated inflation plus real GDP growth. In 2008, wage increases of 16 percent were granted to teachers, health-sector workers, the army, and the police to

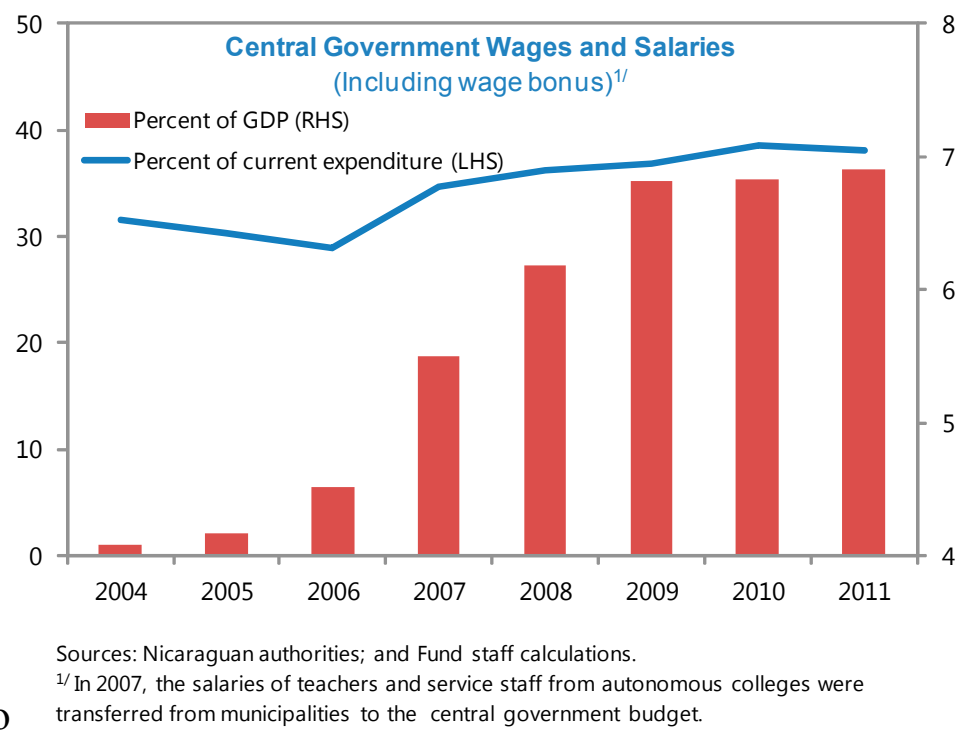
correct lags in wage increases in priority sectors. The 2009 expansionary fiscal package included a real increase of around 9 percent in the public sector wage bill. In May 2010, the government granted an off-budget wage increase for public sector employees (in the form of a monthly bonus at an average annual cost of about 0.7 percent of GDP) financed with grants from Venezuela.

How did the program adjust? Although early program conditionality did not cover wage policies explicitly, these were introduced later, in direct response to the 2010 wage bonus. Staff repeatedly emphasized the importance of containing the wage bill to preserve fiscal sustainability. However, the fiscal consolidation of earlier years was reversed largely because of the rapid increase in wages during 2008-09. The 2010 wage bonus introduced additional risks to the fiscal consolidation objectives and raised transparency concerns. These concerns ultimately delayed the completion of the fourth review. Subsequently, conditionality was strengthened, with the introduction of an indicative ceiling on the wage bill, and the requirement to complete a study assessing the scope for productivity gains and rationalization of government employment. 
Figure 3. Nicaragua: Program Performance-Selected Economic Indicators

(Projections and Outcomes, 2007-11)
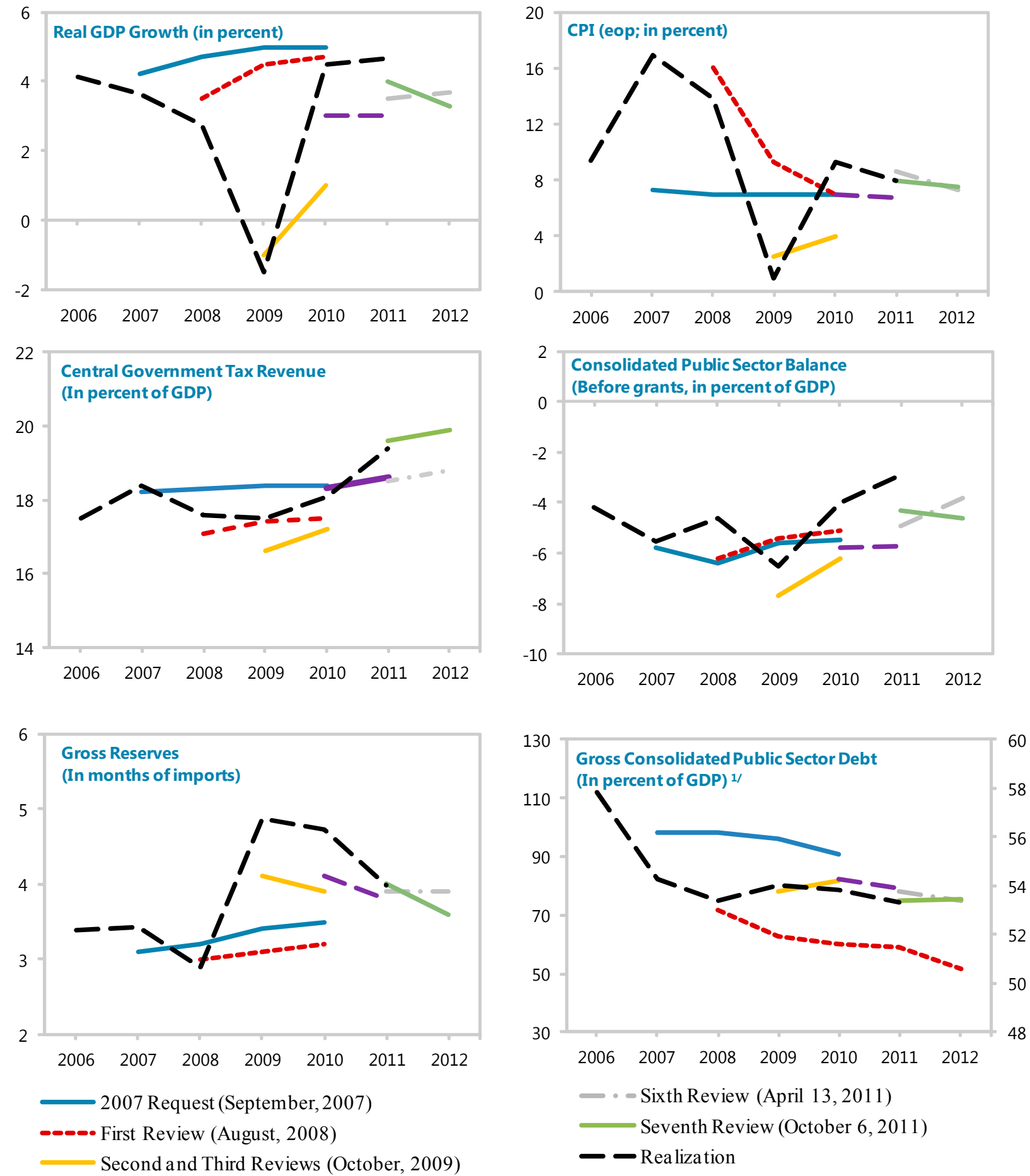

Sources: IMF Staff Reports, 2007-11.

1/ Projections of the 2007 Request and the First Review are on the right axis. 


\begin{tabular}{|c|c|c|c|c|c|c|c|c|}
\hline \multicolumn{9}{|c|}{$\begin{array}{l}\text { Nicaragua: Official External Financing }{ }^{1 /}, 2008-11 \\
\text { (In millions of U.S. dollars) }\end{array}$} \\
\hline & \multicolumn{2}{|c|}{$1^{\text {st }}$ Review } & \multicolumn{2}{|c|}{$2^{\text {nd }}$ and $3^{\text {rd }}$ Reviews } & \multicolumn{2}{|c|}{$4^{\text {th }}$ and $5^{\text {th }}$ Reviews } & \multicolumn{2}{|c|}{$6^{\text {th }}$ and $7^{\text {th }}$ Reviews } \\
\hline & Program & Actual & Program & Actual & Program & Actual & Program & Actual \\
\hline & \multicolumn{2}{|c|}{2008} & \multicolumn{2}{|c|}{2009} & \multicolumn{2}{|c|}{2010} & \multicolumn{2}{|c|}{2011} \\
\hline Total & 135 & 173 & 178 & 90 & 63 & 63 & 62 & 63 \\
\hline IMF & 36 & 49 & 39 & 36 & 20 & 20 & 17 & 18 \\
\hline IDB & 16 & 21 & 21 & 40 & 43 & 43 & 45 & 45 \\
\hline World Bank & 20 & 20 & 20 & 0 & 0 & 0 & 0 & 0 \\
\hline Others & 63 & 83 & 98 & 14 & 0 & 0 & 0 & 0 \\
\hline
\end{tabular}

Sources: Central Bank of Nicaragua; and Fund staff estimates and projections.

${ }^{1 /}$ Includes IMF disbursements and budget support loans and grants.

the resources under the ECF-supported program were not changed and Nicaragua had to lower significantly its reliance on official external financing. ${ }^{8}$

30. Quantitative performance criteria were generally met throughout the arrangement, but the observance of structural conditionality was mixed. With few exceptions, quantitative conditionality was always met, although indicative targets were sometimes missed by small margins (Table 1). The majority of structural benchmarks were met although a number of them with delays and some required revision of test dates or escalation to prior actions. In some instances, delays were caused by the Assembly's approval timing.

\section{Program performance remained broadly satisfactory despite the change in its} objectives in 2009. Even before macroeconomic stability became the primary objective of the program, at the time of the completion of the second and third reviews in 2009, all quantitative performance criteria were met. Compliance with quantitative conditionality was also strong after 2009. A number of the structural benchmarks were met with delays before 2009. Although the structural program facilitated some important reforms, it ceased to be the primary focus of the program in the aftermath of the global financial crisis.

32. Although the program delivered important reforms, it was unable to fulfill some of its original objectives. Key achievements included: the tax reform of 2009; the passage of legislation regulating microfinance institutions; the publication of semiannual reports on the sources and uses of foreign aid, including those from Venezuela; the law establishing economic and penal sanctions for electricity theft; negotiation of a new Electricity Sector Protocol; and the modification of the Central Bank Charter. However, the program was unable to make significant progress in the reforms of the pension system and PFM.

\section{In hindsight, the mixed performance on structural reforms appears to reflect, in} part, the necessary shift of program conditionality toward macroeconomic stability

\footnotetext{
${ }^{8}$ The ECF-supported arrangement included adjustors on the net international reserves, central government expenditure, and the consolidated public sector balance to accommodate fluctuations in external budget loans and grants.
} 
Table 1. Nicaragua: Observance of Conditionality, 2007-11

\begin{tabular}{|c|c|c|c|c|c|}
\hline \multirow[b]{3}{*}{ Quantitative conditionalits } & \multicolumn{5}{|c|}{ Reviews } \\
\hline & First & Second \& Third ${ }^{1 /}$ & Fourth \& Fifth ${ }^{1 /}$ & Sixth & Seventh \\
\hline & \multicolumn{5}{|c|}{ Performance criteria } \\
\hline \multicolumn{6}{|c|}{ Combined public sector overall balance } \\
\hline \multicolumn{6}{|c|}{ Change in net domestic assets } \\
\hline \multicolumn{6}{|c|}{ Change in net international reserves } \\
\hline \multicolumn{6}{|c|}{ Nonconcessional external debt } \\
\hline \multicolumn{6}{|c|}{ Accumulation of external arrears } \\
\hline \multicolumn{6}{|c|}{ Social Security Institute balance } \\
\hline \multicolumn{6}{|l|}{ Indicative targets } \\
\hline \multicolumn{6}{|c|}{ Central government primary expenditure } \\
\hline \multicolumn{6}{|c|}{ Poverty-related expenditure of central government } \\
\hline \multicolumn{6}{|c|}{ Wage bill } \\
\hline \multicolumn{6}{|l|}{ Structural conditionality } \\
\hline \multicolumn{6}{|l|}{ Prior actions } \\
\hline Prior action 1 & Fiscal transparency & Revenue & Pension & \multirow{4}{*}{\multicolumn{2}{|c|}{ Budget }} \\
\hline Prior action 2 & Central bank & Budget & Budget & & \\
\hline Prior action 3 & Financial sector & Budget & Budget & & \\
\hline Prior action 4 & Financial sector & & & & \\
\hline \multicolumn{6}{|l|}{ Performance criteria } \\
\hline Performance criterion 1 & Energy & Budget & & & \\
\hline Performance criterion 2 & Budget & Financial sector & & & \\
\hline \multicolumn{2}{|l|}{ Performance criterion 3} & $\begin{array}{l}\text { Budget } \\
\text { PFM }\end{array}$ & & & \\
\hline \multicolumn{6}{|l|}{ Benchmarks } \\
\hline Structural benchmark 1 & Energy & Fiscal transparency & Budget & Fiscal transparency & Financial sector \\
\hline Structural benchmark 2 & Energy & Revenue administration & Revenue & Civil service & Civil service \\
\hline Structural benchmark 3 & Energy & & Pension & & \\
\hline Structural benchmark 4 & PFM & & Fiscal transparency & & \\
\hline Structural benchmark 5 & Pension & & & & \\
\hline Structural benchmark 6 & Revenue administration & & & & \\
\hline Structural benchmark 7 & Central bank & & & & \\
\hline Structural benchmark 8 & Social sector & & & & \\
\hline \multirow{3}{*}{\multicolumn{4}{|c|}{$\begin{array}{l}\text { Sources: IMF staff reports, } 2007-11 . \\
1 \text { "When the reviews are combined, the colors reflect the status of conditionality at each test date. }\end{array}$}} & \multicolumn{2}{|l|}{ Met } \\
\hline & & & & \multicolumn{2}{|l|}{ Met with delay } \\
\hline & & & & Notmet (pending o & opped) \\
\hline
\end{tabular}


objectives in 2009. As noted, the global financial crisis heightened the importance of increasing the resilience of the macroeconomic framework in order to better cope with the turbulent global environment. Areas that required greater resolve and ownership, such as pension, governance, and institutional reforms, were only partly addressed by conditionality, especially in later stages of the program.

34. The authorities' ownership of the program also seems to have been in some instances overestimated. For instance, the decision not to include quantitative conditionality on wage policy and the energy sector in the initial stages of the program appears to suggest confidence in the authorities' resolve, given that these issues had led to major challenges in some of the previous programs with Nicaragua. In the case of wage conditionality, the program was possibly also reflecting shift in the conditionality guidelines to overall spending and priority items rather than individual budget items. The program employed a relatively high number of prior actions many of which focused on submission of a budget or a supplementary budget. This in turn implies that ownership was not sufficient enough to deliver the program targets in a timely fashion.

\section{Technical Assistance}

35. The program was supported by significant technical assistance from the Fund. Technical assistance was particularly helpful to the achievement of program objectives on the fiscal area. For example, TA support was critical in the design of some revenue reform initiatives that became part of the 2009 tax reform. The Fund also provided TA through the Regional Technical Assistance Center (CAPTAC-DR) to develop a multi-year plan to improve the effectiveness, transparency, and accountability of public expenditures. TA from the CAPTACDR was also instrumental in formulating the necessary steps to improve customs regulations and to enhance the BCN's liquidity management facilities. The 2009 Financial Sector Assessment (FSAP) Update focused on a number of issues closely related to areas of structural program, including banking system issues, monetary operations and public debt, access to finance and microfinance regulation, and financial system infrastructure.

\section{E. Collaboration with Other IFIs}

\section{The collaboration with the World Bank and the IDB led to tangible gains in a} number of structural reform areas some of which are outside the Fund's core expertise. A notable example is the Fund's close coordination with the World Bank and IDB in the design of energy sector reforms. The World Bank also played a pivotal role in the preparation of the new regulatory framework for microfinance institutions. The IDB provided the terms of reference for the preparation of the report on public sector employment, which constituted a structural benchmark. 


\section{Medium-Term Structural Policy Challenges}

\section{A. Stability and Growth: Half Full or Half Empty?}

37. Nicaragua has been successful in preserving macroeconomic stability in the last decade. During this period, Nicaragua was able to complete two broadly successful Fundsupported programs and experienced a significant decline in macroeconomic volatility and inflation. In addition, it recorded robust growth in exports and FDI inflows, especially in comparison with its regional peers. Increasing integration into the world economy has helped align Nicaragua's business cycle with the global cycle (Figure 4).

38. However, Nicaragua's growth performance has been weak and lagging its regional peers. After experiencing a traumatic decline in GDP at the end of the 1970s and in the 1980s with recovery over the $1990 \mathrm{~s},{ }^{9}$ the country has been able to grow but not fast enough to make a significant dent in poverty and income inequality. Despite safeguarding macroeconomic stability and expanding trade and FDI flows, Nicaragua's per capita income growth has averaged an annual rate of 1.3 percent over the past two decades much lower than the average for Central American countries (2.5 percent). Its productivity growth has also been low, and it has consistently ranked lower than the typical Central American country in most indicators of competitiveness and development (Figure 5).

39. Why has Nicaragua not been able to grow faster? A major reason seems to have been the patchy implementation of structural reforms that has prevented the country from overcoming key bottlenecks to growth: protracted challenges of the energy sector and pension system; weak institutions and governance; scarcity of human capital; poor infrastructure; underdeveloped financial markets; and a low level of private sector development. The Fund-supported programs, including the 2007 ECF-supported arrangement, clearly identified these bottlenecks and helped make some progress in eliminating some of them. Notwithstanding this progress, broader reform efforts have often faded away due to lack of political consensus.

40. Nicaragua needs to make steady progress in unlocking the main constraints to higher growth through structural reforms. Reforms would not just increase output growth, but would also amplify the gains from Nicaragua's increased trade and FDI flows. For example, infrastructure improvements, including the reform of the electricity sector, could lead to a significant increase in growth benefits associated with trade integration. Moreover, given its low level of development, the growth gains stemming from reforms in Nicaragua tend to be much

\footnotetext{
${ }^{9}$ Edwards (1992) and Ocampo (1992) present surveys of macroeconomic developments in the late 1980s and early 1990s in Nicaragua.
} 
Figure 4. Nicaragua: Stability and Integration: Half Full?
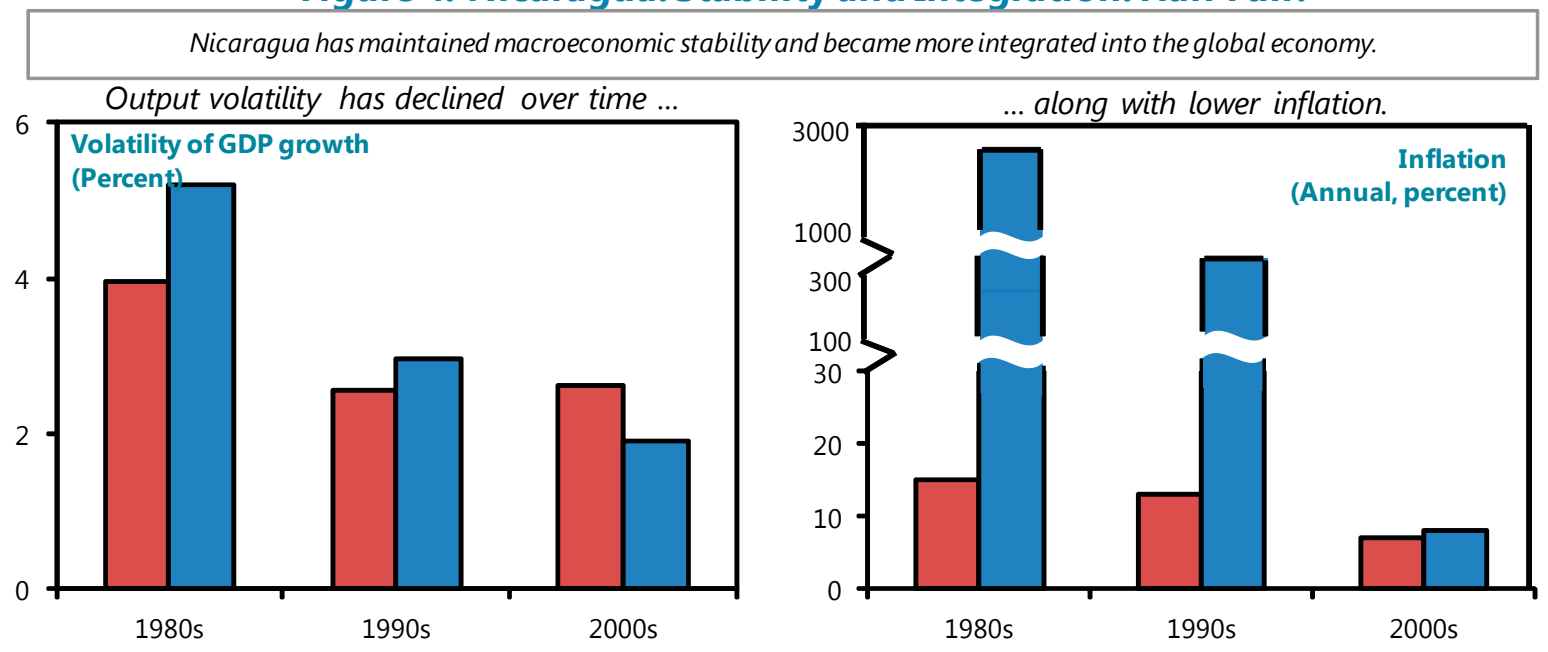

Also, exports have increased rapidly...

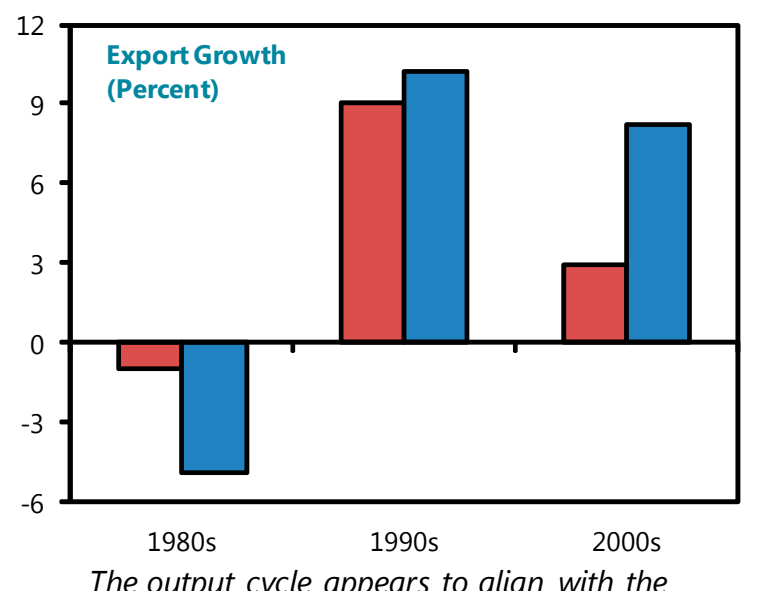

...in tandem with a significant increase in FDI inflows.

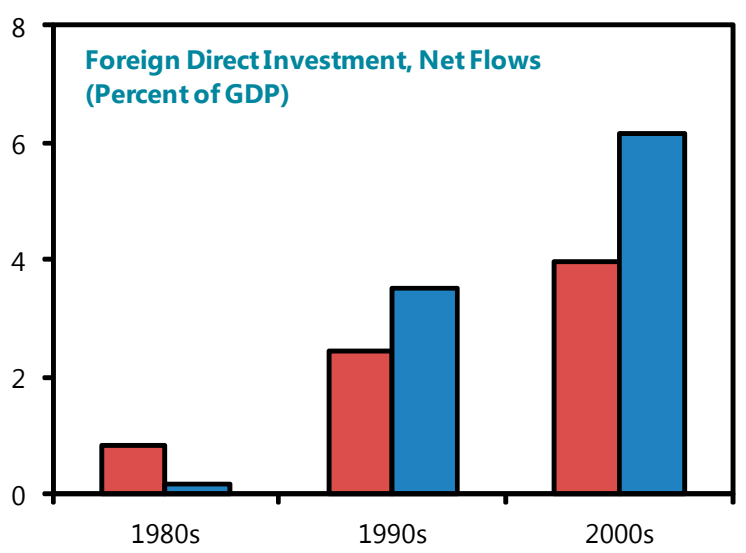

... though the comovement in private global cycle ...
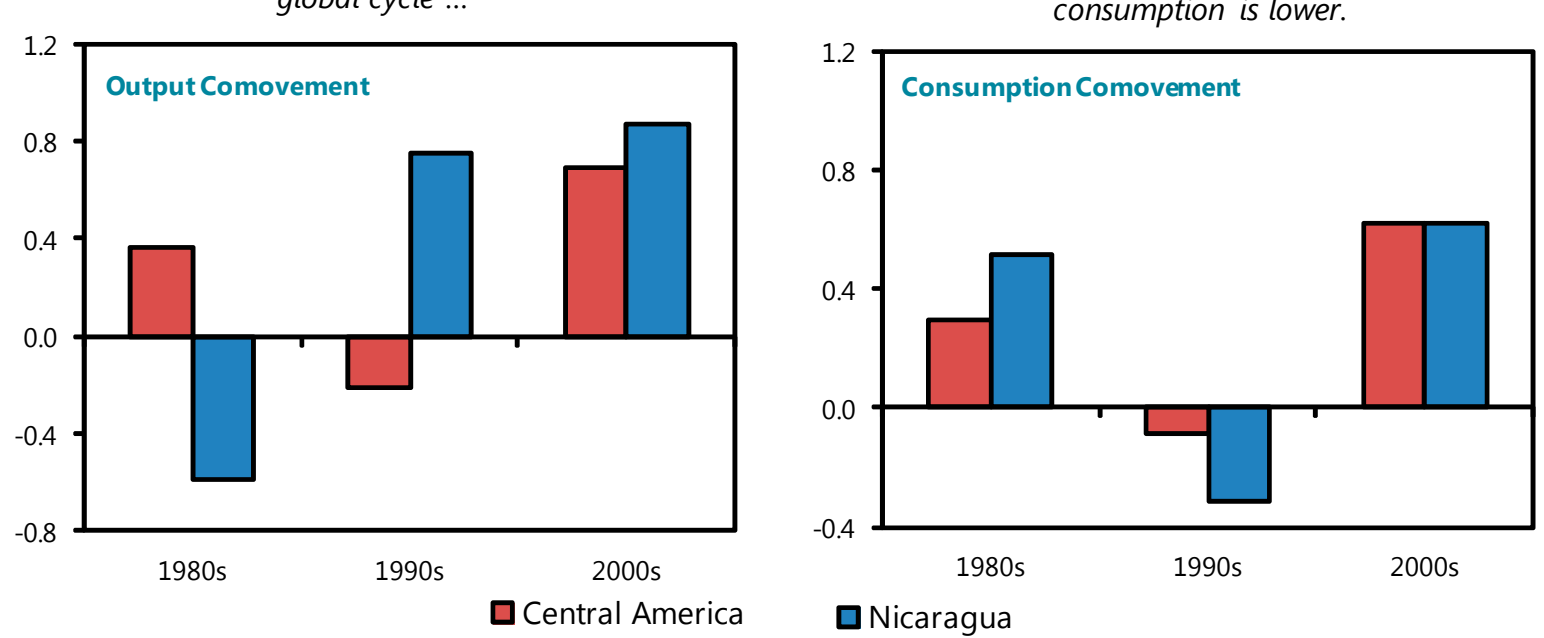

Sources: IMF Staff Estimates. All data except FDI are from WEO, FDI data are from WDI.

Notes: Output comovement refers to the correlation between domestic and global GDP growth. Consumption comovement refers to the correlation between domestic and global consumption growth. Central America refers to the average of Costa Rica, Dominican Republic, El Salvador, Honduras, Guatemala, and Panama. 
Figure 5. Nicaragua: Growth and Development: Half Empty?

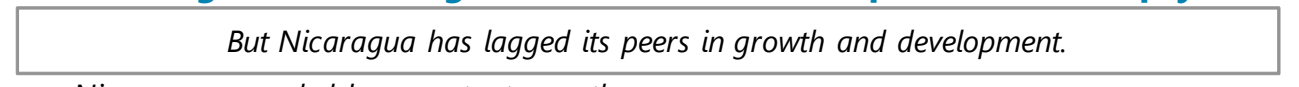

Nicaragua recorded lower output growth per capita than its peers ...

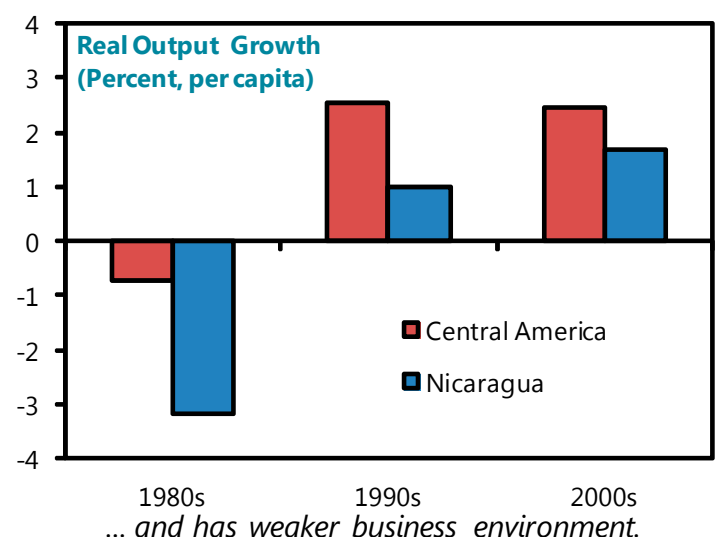
... scored relatively lower in most indicators of competitiveness.
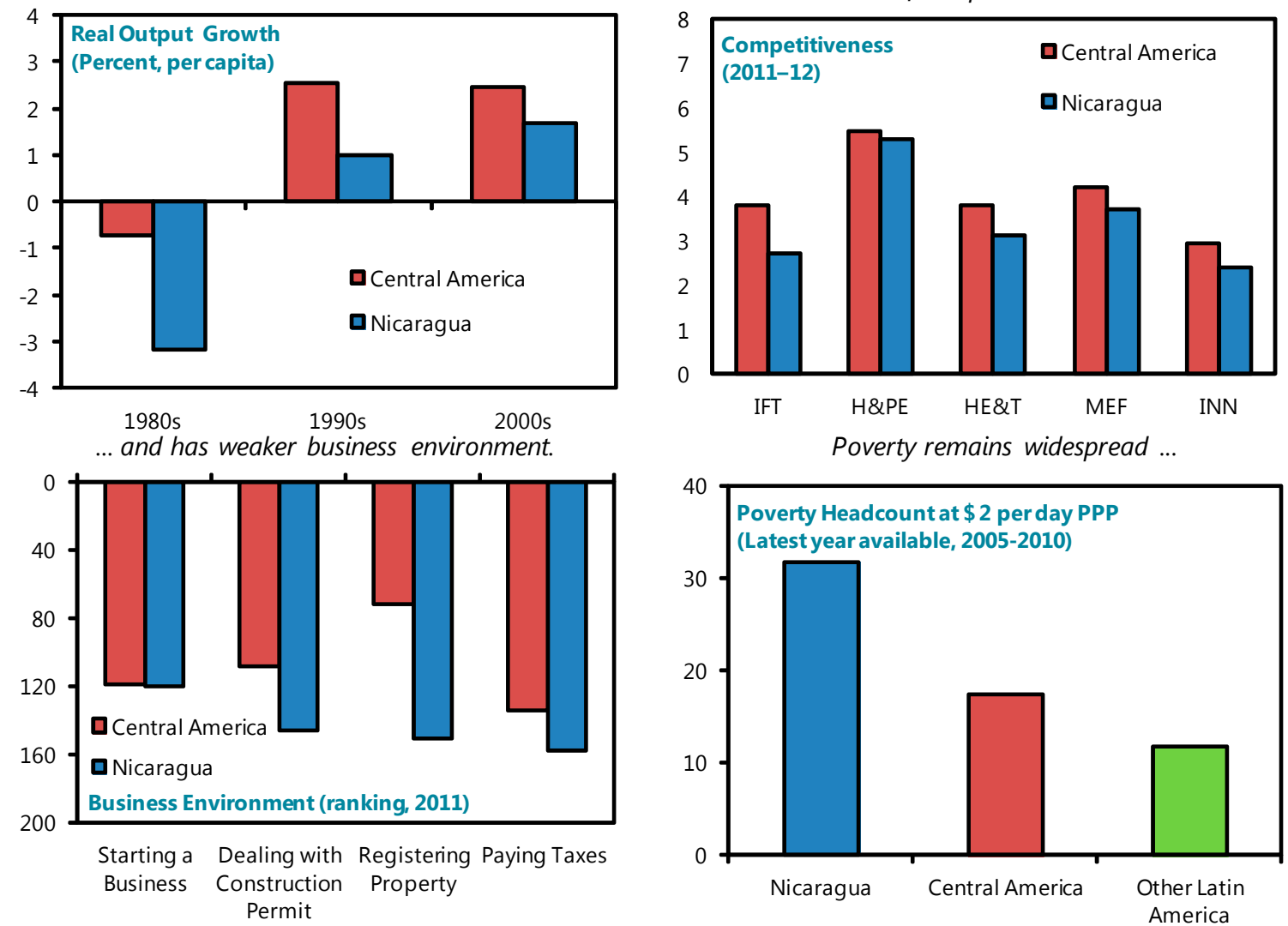

... and other development indicators, including access to electricity ...
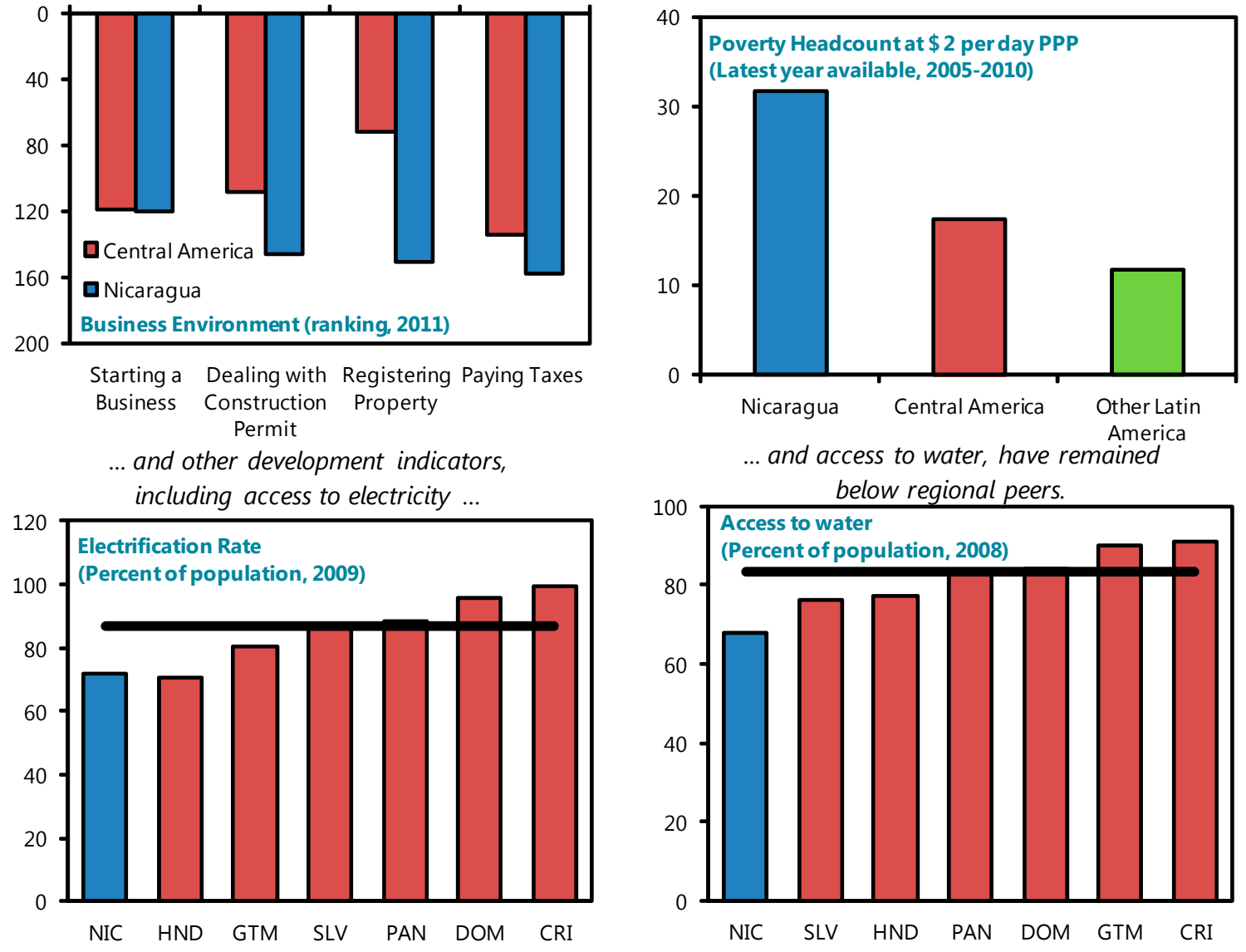
... and access to water, have remained

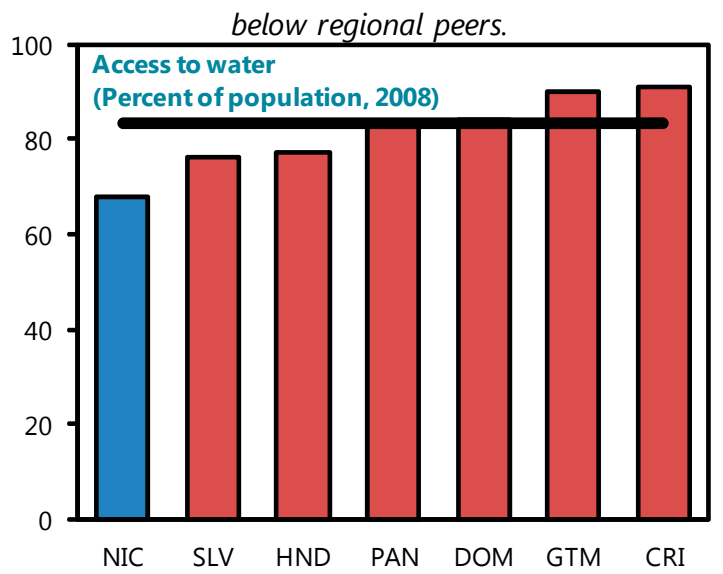

Sources: GDP per capita data are from WEO. The competitiveness figure presents the competitiveness scores from The Global Competitiveness Report 2011-2012 of World Economic Forum. The business environment figure presents the Doing Business Indicators from the World Bank. Poverty headcount and access to water are from the WDI database of the World Bank. Electrification rate presents data from World Energy Outlook 2011 of International Energy Agency.

Notes: Black lines show the average of the Central American countries, except Nicaragua.

IFT: infrastructure, H\&PE: health and primary education, HE\&T: higher education and training, MEF: market efficiency, INN: innovation. 
larger than those in other Central American countries. ${ }^{10}$ Although structural reforms are clearly necessary to improve the growth performance of Nicaragua, eradicate poverty, and increase the resilience of the economy, they can be implemented only if there is a broad political and public consensus. $^{11}$ The rest of this section summarizes the challenges in key areas of structural reform that need to be addressed in the medium term.

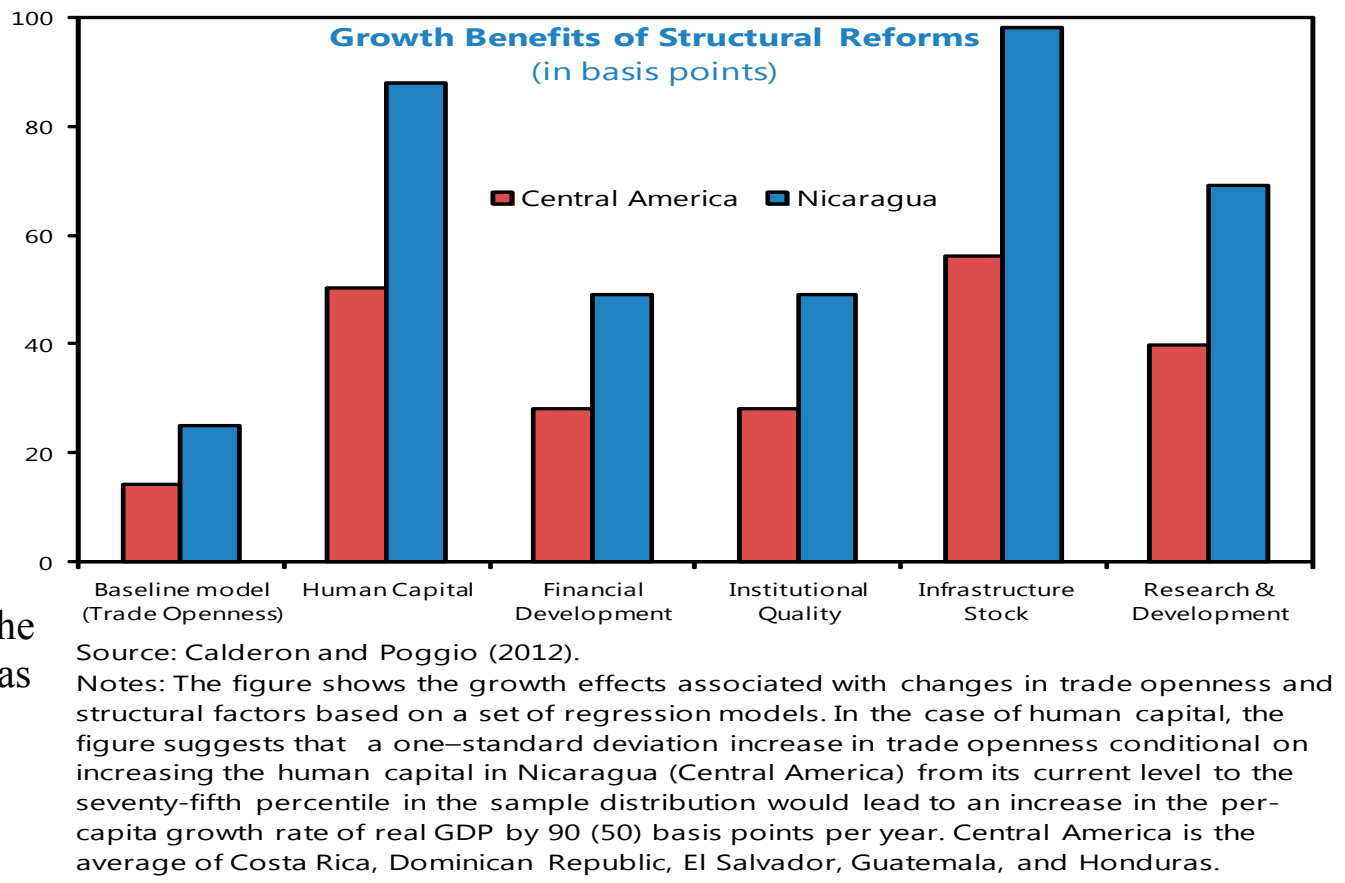

\section{B. Energy Sector Reforms}

\section{Despite the progress in recent years, Nicaragua's electricity sector continues to face} serious challenges and remains an impediment to growth. More than two-thirds of the country's electricity is still generated by (expensive) fuel-oil based plants, and electricity tariffs have often been below generation costs. Moreover, non-technical losses remain large causing liquidity problems for electricity distribution. Although overall electrification rate has increased quite substantially from 47 percent in 2003 to 72 percent in 2009, it is still low by regional standards, suggesting further room for improvement.

\footnotetext{
${ }^{10}$ The text figure shows the growth effects of a one-standard deviation increase in trade openness according to a model developed by Calderon and Poggio (2012). Other models show the growth effects of a one-standard deviation increase in trade openness when the indicators of structural factors are also increased to the $75^{\text {th }}$ percentile of the world distribution in 2006-10.

${ }^{11}$ Recent studies show that trade and financial integration tend to translate into larger growth gains when a country implements complementary reforms to improve its financial sector development, labor market flexibility, institutions, infrastructure, and regulatory framework (see Chang, Kaltani, and Loayza, 2009; Kose, Prasad, and Taylor, 2011; Calderon and Poggio, 2012; Swiston and Barrot, 2011). Calderon and Poggio (2012) run a series of panel regressions using a large sample of countries to assess how the growth effects of increasing trade openness for CAFTA-DR countries change conditional on structural factors and policies. They report that trade integration leads to much larger growth gains when complemented by structural reforms in Nicaragua than it does in a typical Central American country. Harberger (2007) also argues that structural reforms and robust macroeconomic policies can have a significant impact on Nicaragua's growth prospects.
} 


\section{Addressing challenges in the energy sector would improve Nicaragua's growth} prospects and reduce vulnerabilities. ${ }^{12}$ A viable electricity sector would require updating the parameters of the Electricity Sector Protocol, with a view to securing the finances of the sector. Mindful that such an update may imply higher tariffs for consumers, it should be accompanied by measures aimed at improving the targeting of subsidies to protect the most vulnerable segments of the population. Investments in the sector to reduce technical and non-technical losses, along with efforts to increasing service coverage, as well as diversification to nonexhaustible electricity generation plants, would be critical for ensuring the long-term sustainability of the sector. In addition, it would be useful to consider the possibility of undertaking Public Private Partnerships (PPPs) to increase investment in the sector after making sure that the institutional framework consistent with best international practice.

\section{Fiscal Structural Reforms and Debt Management}

\section{Pension Reform}

43. The current parameters of the pension system imply a long-run imbalance between contributions and benefits. The coverage of the system is among the lowest in Latin America, with less than one quarter of the total working age population contributing to the system. Large increases in minimum pension payments, rapid growth of administrative costs, and expansion in medical insurance coverage since 2007 have aggravated the already precarious long-term finances of the social security administration (INSS). Moreover, according to actuarial estimates, pension contribution rates must increase to over 30 percent to maintain the current level of benefits over the next 50 years. In the absence of any changes, the system is projected to incur a cash deficit and become insolvent during the next decade. ${ }^{13}$

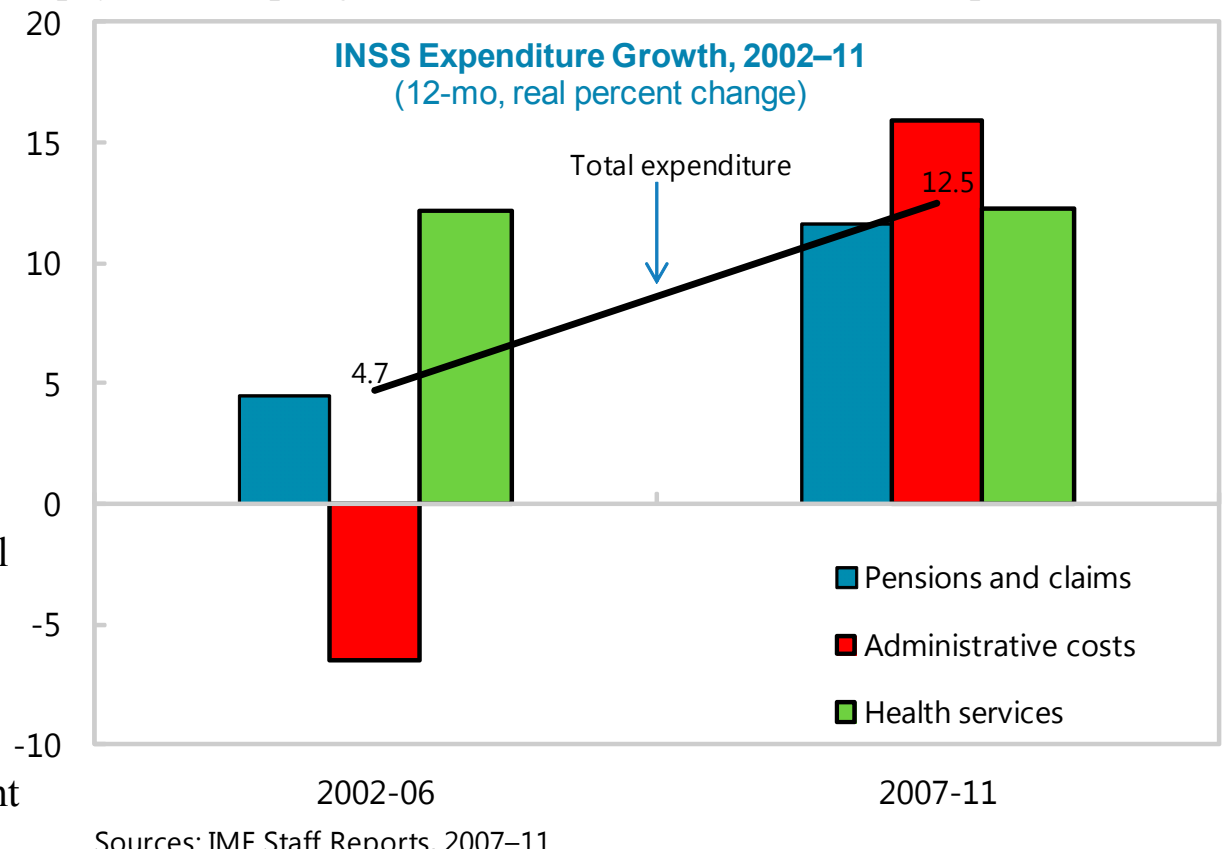

\footnotetext{
${ }^{12}$ The reform of the electricity sector is also critical in reducing the chronically high current account deficit in Nicaragua. As noted in Chapter III of the 2012 Article IV Selected Issues Paper, further reforms in the sector could lead to a decrease in the oil import bill of about 3-4 percent of GDP per year, which would reduce pressure on the external current account.

${ }^{13}$ See Staff Report for the 2010 Article IV.
} 
44. Significant progress on pension reforms is necessary to ensuring fiscal sustainability over the medium term. The INSS published a report on options to reform the pension system in 2010. The report includes various parametric reform options to strengthen the financial position of the system, including, among others, by raising contribution rates, increasing retirement age, reducing benefits, lowering replacement rates, abolishing minimum pension, and developing a complementary fully-funded pension system. Despite repeated attempts in the past Fundsupported programs, progress on pension reforms has often been stalled owing to political economy constraints. Moving on the necessary reforms would require strong resolve and continued consensus building, and should be phased in gradually taking into account potential transition costs.

\section{Tax policy, revenue administration, and public financial management}

45. Revenue intake increased during the last program, but weaknesses remain in the area of tax policy and revenue administration. It would be important to lock in the gains from the 2009 tax reform with continued improvements that focus on: (i) broadening the tax base by eliminating tax exemptions, which remain large (about 8 percent of tax revenues in 2010), particularly in VAT and corporate income taxes; and (ii) simplifying the tax system while enhancing the efficiency of revenue administration.

46. Nicaragua needs to embark on a comprehensive PFM reform. The multi-year Financial Management System Modernization Plan (for 2008-12) provides the main ingredients of the PFM reform to enhance expenditure control and planning, increase budget flexibility, and improve efficiency, transparency and accountability in public finances. Existing budget rigidities, reflecting the constitutionally-mandated transfers of 10 percent of revenues to universities and the judiciary, continue to pose challenges in the reallocation of spending towards priority areas. Moreover, a weak link between the multi-year budget framework and the annual budget, and the absence of a coherent medium-term framework to guide wage policy are key problems in managing Nicaragua's public finances.

47. The efficiency of public investment spending also should be enhanced. Despite Nicaragua's large share of public investment spending relative to that of its regional peers, its

Nicaragua: Public Investment and Infrastructure Quality, 2007-11

\begin{tabular}{lcccccc}
\hline & \multicolumn{3}{c}{ Public Investment (percent of GDP) } & \multicolumn{2}{c}{$\begin{array}{c}\text { Infrastructure } \\
\text { Quality Rank }\end{array}$} \\
\cline { 2 - 6 } & 2007 & 2008 & 2009 & 2010 & 2011 & 2011 \\
\hline Nicaragua & 5.4 & 5.7 & 7.1 & 7.4 & 7.1 & 116 \\
Costa Rica & 3.2 & 4.0 & 3.6 & 4.2 & 3.6 & 83 \\
Dominican Republic & 5.2 & 5.0 & 3.6 & 3.8 & 3.3 & 106 \\
El Salvador & 2.2 & 2.4 & 2.2 & 2.1 & 2.1 & 65 \\
Honduras & 4.0 & 4.6 & 3.4 & 4.0 & 3.2 & 91 \\
Panama & 5.6 & 8.2 & 9.4 & 12.8 & 14.1 & 38 \\
Average & $\mathbf{4 . 0}$ & $\mathbf{4 . 8}$ & $\mathbf{4 . 5}$ & $\mathbf{5 . 4}$ & $\mathbf{5 . 3}$ & $\mathbf{7 6 . 6}$ \\
\hline Sources: IMF, World Economic Outlook; Global Competitiveness Reports, 2011-2012 \\
Notes: Ranking is out of 142 countries. Public investment refers to gross fixed capital formation in \\
percent of GDP.
\end{tabular}


infrastructure quality indicators are among the lowest in the world. Although some progress was achieved in public investment management during 2007-11, there still is a clear need to boost the effectiveness of the PFM system, including by enhancing public investment management process (project selection, appraisal, implementation, monitoring and evaluation); improving coordination between budgeting and planning; and strengthening internal and external controls.

\section{Debt Management}

48. The debt-to-GDP ratio remains the highest in the region owing in part to the slow progress in achieving the necessary fiscal consolidation and securing debt relief from nonParis Club creditors. Nicaragua reached the HIPC completion point in 2004 and received substantial debt relief from all Paris Club creditors. ${ }^{14}$ However, negotiations for further debt relief on HIPC-equivalent terms from some non-Paris Club bilateral creditors have been proceeding at a slow pace since then. ${ }^{15}$ The composition of debt improved only slightly during the last program, with the share of (expensive) domestic debt falling by about 3 percent.

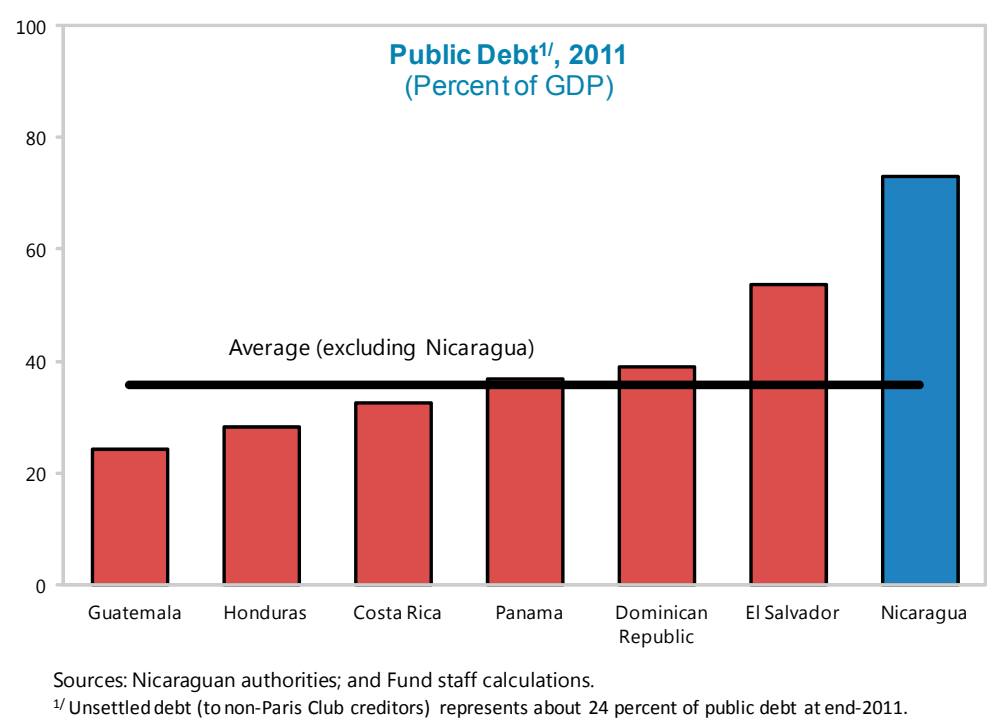

49. It would be important to reduce public debt over the medium term and improve its composition. Nicaragua continues to face only moderate risks of external public debt distress, but vulnerabilities remain, and largely stem from worsening financing terms, lower-thanenvisaged medium-term growth, slower-than-expected external adjustment, and deterioration in the social security's operating balance. Nicaragua's domestic public debt is denominated in foreign currency and, thus, sensitive to exchange rate shocks, which points to the need to gradually diversify the currency composition of debt. Going forward, Nicaragua needs to accelerate negotiations with the non-Paris Club creditors to secure further debt relief. That said, a sustained decline in the debt ratio would continue to hinge on continued fiscal consolidation.

\footnotetext{
${ }^{14}$ The program envisaged a gradual decline in public debt over the medium term while creating fiscal space for priority spending, but multiple shocks Nicaragua experienced during the program made it difficult to make significant gains on the fiscal consolidation front. Despite these challenges and the slow progress in negotiations for further debt relief, the public debt-to-GDP ratio declined during the period (from 82 percent in 2007 to 73 percent in 2011).

${ }^{15}$ Non-Paris Club bilateral creditors include Costa Rica, Libya, Taiwan POC, Iran, Honduras, Peru, China, Uruguay, India, and Ecuador. Debt to these creditors accounted for 24 percent of the outstanding public debt (17.5 percent of GDP) at end-2011.
} 


\section{Monetary and Financial Sector Reforms}

50. The crawling-peg regime appears to be a sensible choice, but monetary policy operations can be improved. Given that Nicaragua is a highly dollarized economy susceptible to external shocks, and monetary policy is conducted in the context of a wide range of imbalances, it seems appropriate to anchor the policy framework on a crawling-peg regime. Moreover, the regime has served well especially over the past decade by providing a nominal anchor for monetary policy and stabilizing inflation expectations around the pre-determined rate of crawl (of 5 percent), while preserving competitiveness. However, 100 there is room to enhance monetary policy operations by developing a more liquid interbank money market and improving reserve requirement regime. It would also be useful to review alternative exchange rate regimes, with a view to assessing options over the longer term.

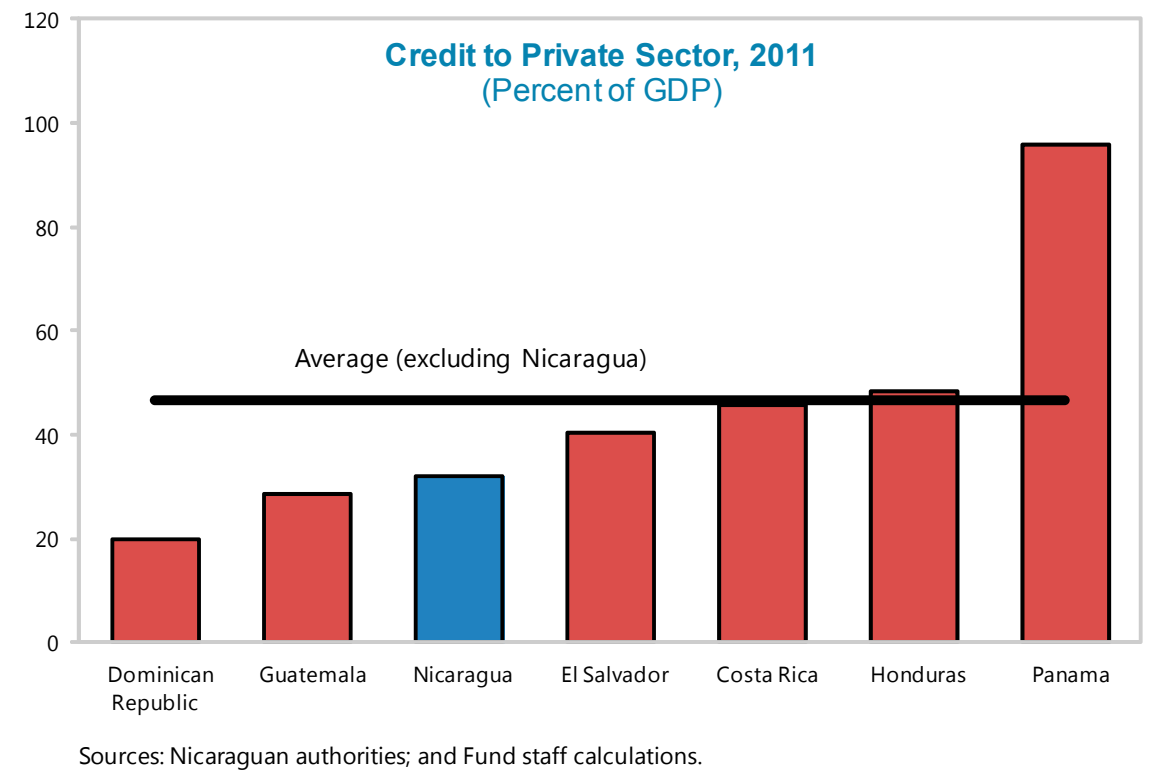

51. Although the financial sector was resilient during the global financial crisis, many structural challenges remain. The financial sector is dominated by regional banking groups (mainly incorporated in Panama), which represent more than 80 percent of the banking sector's assets, with high concentration in the two largest banks. The small scale of the system, its high concentration, and relatively high country-risk premium hinder greater competition in the sector. Financial intermediation, measured by the share of credit to the private sector, is among the lowest in the region. Moreover, difficulties to perform comprehensive assessment of financial conditions of the Nicaraguan regional groups operating abroad due to information shortcomings could pose risks.

52. Addressing these challenges, including through the swift implementation of the 2009 FSAP Update Recommendations, would be crucial to enhance the stability and efficiency of the financial system. Priority reforms should include: (i) improving banks' regulation, risk management and oversight; (ii) enhancing the efficiency and competition in the banking sector; (iii) strengthening consolidated and cross-border supervision; (iv) and upgrading monetary policy management by enhancing liquidity operations.

\section{E. Governance Reforms and Private Sector Development}

53. The quality of governance in Nicaragua has continued to deteriorate. In particular, indicators of voice and accountability, government effectiveness, and control of corruption (compiled by the World Bank) have been declining over the past decade. Moreover, "Doing 
Business" indicators of the World Bank suggest that Nicaragua compares less favorably to the average of Central American countries on account of weaknesses in several dimensions, including starting a business, registering property, paying taxes, trading across borders, and getting electricity.

\section{Further efforts are} needed to improve the quality of institutions, transparency, and business climate. It is

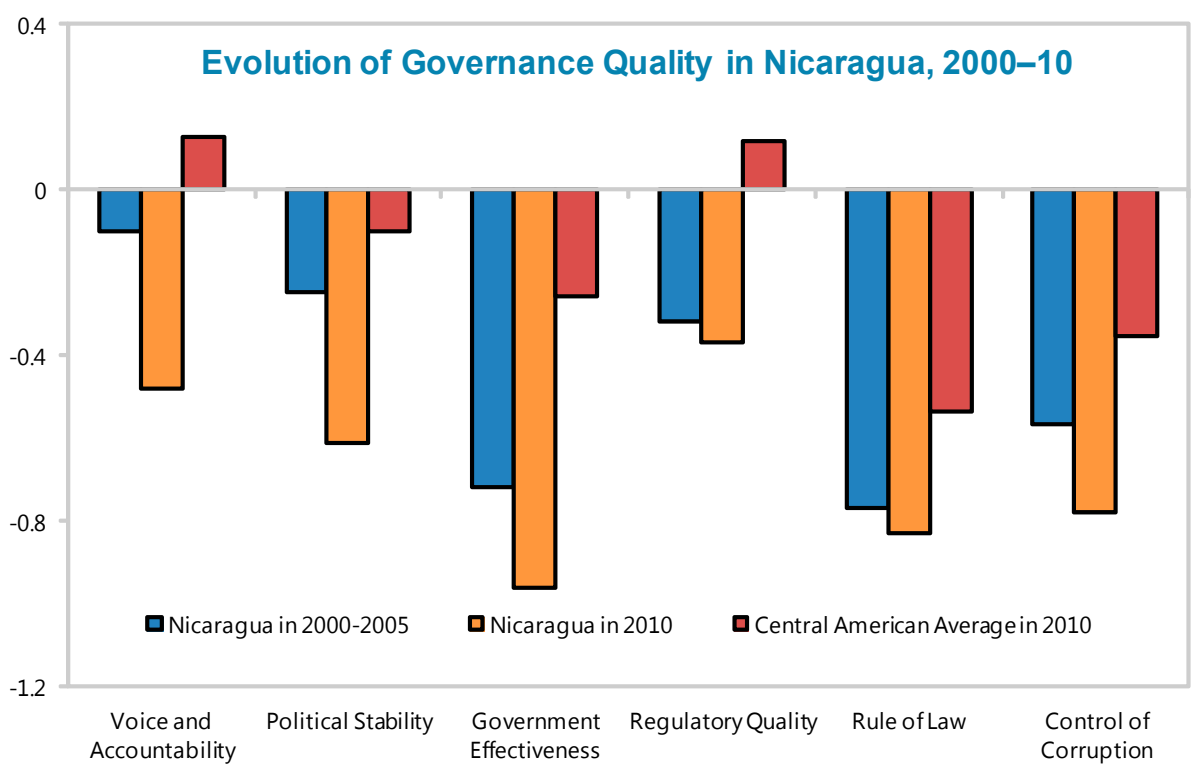

Source: Worldwide Governance Indicators, World Bank Notes: Each indicator represents the estimate of governance quality which ranges from approximately -2.5 (weak) to 2.5 (strong) governance performance. critical to enhance institutional and regulatory frameworks by depoliticizing public institutions and promoting transparency to strengthen policy formulation. It would be equally important to improve the land registration system to increase the certainty of property titles. In addition, Nicaragua needs to undertake reforms to reduce informality in labor and product markets. These measures would enhance the business climate and promote private investment, and ultimately would help Nicaragua leverage the opportunities afforded by CAFTA-DR and regional economic integration, while unleashing its growth potential.

\section{Transparency, monitoring and governance of aid flows also remain an outstanding} concern. As explained in Box 2, the macroeconomic and governance implications of aid inflows are significant. Despite the progress over the past two years, it would be necessary to take precautionary measures to mitigate the impact of these flows on macroeconomic stability and to improve governance of domestic private institutions (among them CARUNA) affiliated with the Nicaragua-Venezuela/ALBA collaboration by publishing their audited financial statements.

\section{F. Poverty Reduction and Social Policy Reforms}

\section{Despite recent gains, more progress is needed towards achieving the Millennium}

Development Goals (MDGs). Nicaragua has made good progress towards achieving the MDGs with respect to the targets on extreme poverty and child mortality rate. However, poverty is still very high and there are concerns for sustained future performance in relation to several other goals, including with respect to the targets on universal primary education and maternal health (see Appendix IV). Missing these targets would be particularly worrisome given their long-term implications for the well-being of large segments of the population and for building human capital. 


\section{Social policies are anchored in the government's Poverty Reduction Strategy Paper} (PRSP). Implementation of the five strategic pillars of the PRSP could lead to marked improvements in living standards over the medium term. ${ }^{16}$ Successful implementation of the strategy, though, hinges on continued improvement in governance and PFM systems through increased transparency in public finances, and enhanced monitoring and evaluation of social programs. The great challenge continues to be reducing poverty in rural areas where poverty is deeper. Further work, including through impact analysis, would be needed to ascertain the contribution of different factors, including the role of social programs, on the observed changes in social indicators.

\section{WHAT LESSONS FOR THE FUTURE?}

\section{A. Summary Assessment and Lessons Learned}

58. The 2007 Fund-supported program played a major role in helping preserve macroeconomic stability. Despite a series of shocks, including the global financial crisis, the program was effective in helping the Nicaraguan authorities design and adopt a realistic policy framework. The basic indicators of vulnerability remained largely stable: the Fund's advice was instrumental in keeping inflation,

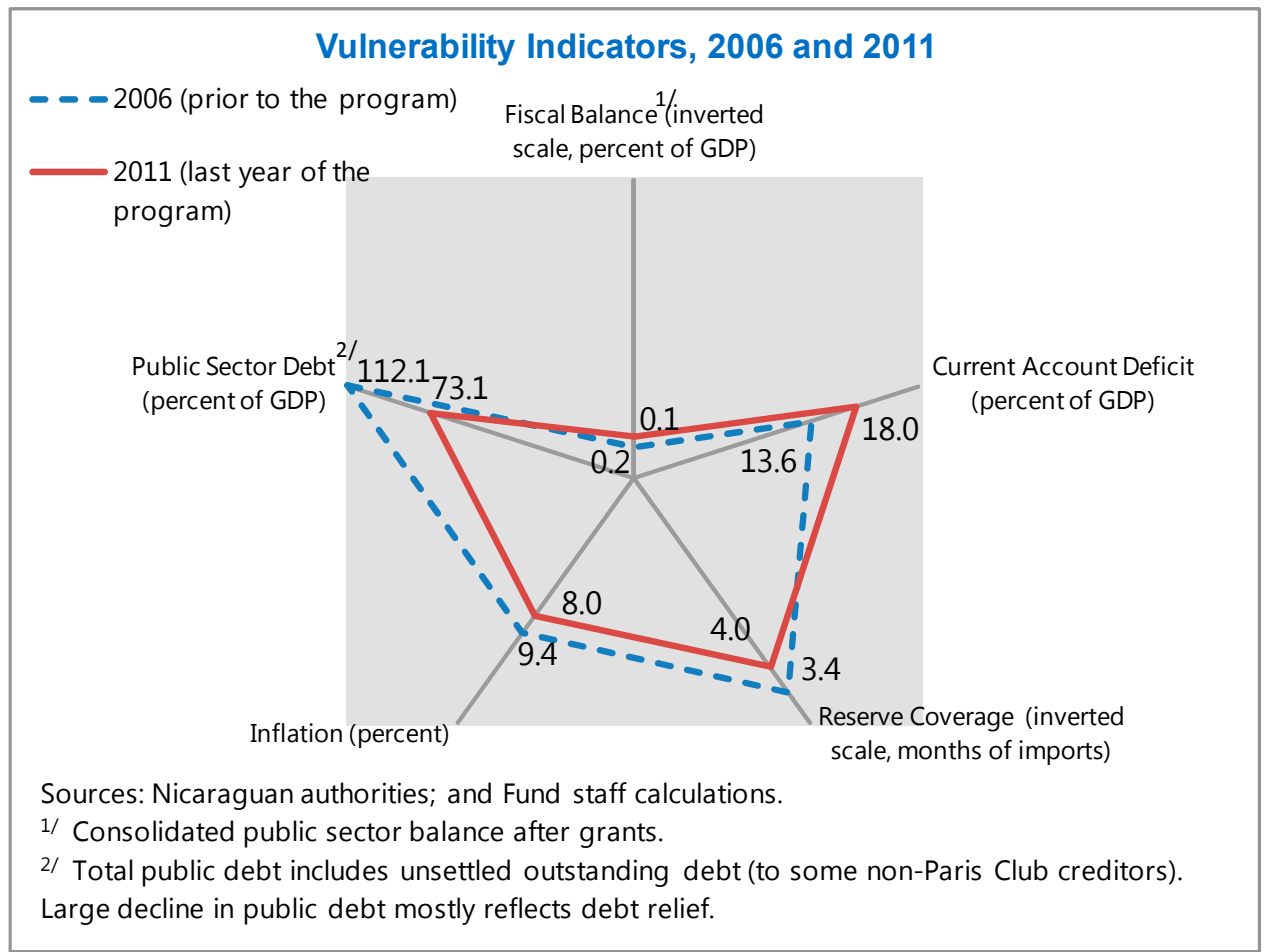
and the fiscal and current account balances ${ }^{17}$ under control, while

${ }^{16}$ The PRSP was updated in 2011, in coordination with the World Bank, and includes the following pillars: (i) promoting growth through sound macroeconomic policies, increased public and private investments, and improved access to external markets; (ii) fostering well-being and equity through the expansion of health and education services, and targeted social programs aimed at supporting production of poor households; (iii) improving the governance and transparency of public sector institutions (iv) promoting environmental sustainability; and (v) reducing inter-regional disparities.

${ }^{17}$ A significant fraction of the current account deficit in Nicaragua is explained by the oil import bill. Exports and remittances increased, but the price of oil went up significantly more during the program (from US\$71 per barrel in 2007 to US\$104 per barrel in 2011). 
beefing up the country's foreign reserve buffer. ${ }^{18}$ It is difficult to design a counterfactual without a Fund-supported program, but the outcome for the Nicaraguan economy would most likely have been worse.

59. However, progress in structural reforms during the program period was uneven. The ECF-supported program paved the way for completing some tax reforms and the energy sector reforms. In addition, it correctly focused on the implications of rapid increase in aid flows, including those from Venezuela, and played a critical role in enhancing their transparency. However, the program fell short of making progress in some key structural areas, such as pension and PFM reforms.

60. Program design was flexible but the confluence of weak ownership and intensity of exogenous shocks led to implementation challenges. There were persistent delays in the first three years of the program, primarily because of various shocks, including the global financial crisis, and policy slippages. Conditionality evolved over time as the program adjusted to changes in the global environment. For example, in the aftermath of the global financial crisis, the program shifted its focus to safeguarding macroeconomic stability and building a track record in late 2009. However, there were also instances when weak ownership ownership resulted in the postponement of reviews, delays in meeting some elements of structural conditionality, and its streamlining in certain areas. These in turn caused the reform agenda to take a back seat to shortterm objectives as the program increasingly focused on preserving macroeconomic stability.

61. The evolution of the $\mathbf{2 0 0 7}$ program exhibits some striking parallels with the 2002 program. Notable similarities include: (i) unexpected large wage increases that led to delays of some of the reviews; (ii) fiscal policy slippages that caused modifications in the macroeconomic program, while political tensions slowed the structural reform agenda; (iii) lack of ownership reflected in the uneven implementation of structural reforms; (iv) both programs went off track for a prolonged period of time and experienced multiple instances of combined reviews - a total of seven reviews in the 2007 program and 11 in the 2002 program; and (v) despite these difficulties of implementation, both programs were eventually completed in four years with broadly successful macroeconomic outcomes.

\section{The Fund's engagement with Nicaragua has been challenging, but the similarities between the last two completed Fund-supported programs point to three useful lessons:}

- $\quad$ Being flexible is key to achieve broad objectives. Both programs were flexible in adapting to changing circumstances in order to safeguard macroeconomic stability. In particular, the shift in the focus of the last program in 2009 was vital in designing an effective policy strategy to

\footnotetext{
${ }^{18}$ The program design envisaged a gradual increase in international reserve coverage. It was partially successful in achieving this objective as reserve coverage increased during the program period from 3.4 months of imports in 2006 to four months of imports in 2011. Nicaragua's reserve coverage is above the standard rules-of-thumb (as noted Chapter II of the 2012 Article IV Selected Issues Paper). Based on a new methodology developed by the Fund staff in 2011, depending on the unit cost of holding reserves, the optimal level of reserve coverage for Nicaragua is between three and six months of imports suggesting that Nicaragua's reserve coverage could be further increased.
} 
mitigate the adverse impact of the global financial crisis on Nicaragua. Both programs correctly emphasized the importance of improving the country's track record in Fund-supported arrangements.

- $\quad$ But being persistent is imperative to deliver on critical targets. Both programs were able to achieve broadly successful fiscal outcomes by insisting on the need to adhere to prudent fiscal policies. This strategy led to the postponement of reviews at times, but it was obviously vital to keep fiscal deficits under control. For example, there was a delay in the completion of the second and third reviews in 2009 , but the authorities correctly modified the focus of the program and undertook a series of measures to arrest the deterioration in the fiscal position.

- $\quad$ And having foresight helps a lot. Both programs correctly recognized the potential domestic risks ahead of time enabling the speedy formulation of necessary policy responses when these risks materialized. This is critically important in light of Nicaragua's challenging political environment and weak institutions.

\section{B. Strategy for Future Fund Involvement}

\section{Fund Involvement}

63. Nicaragua could benefit from continued program engagement with the Fund. Although Nicaragua has achieved some degree of macroeconomic stability, its economy is still fragile and faces significant growth challenges requiring the implementation of a comprehensive structural reform agenda. The Fund's advice under the framework of a program could help preserve macroeconomic stability and make progress in structural reforms. A surveillance-only relationship with the Fund would imply a less intense and frequent policy dialogue, and it would be less effective in maintaining policy discipline to safeguard stability and in making progress on the structural reform agenda.

64. The case for continued engagement hinges on whether a prospective Fundsupported program is able take into account the challenges faced by earlier arrangements. Specifically, a possible future program should have the following features: (i) it needs to be backed by strong ownership; (ii) it should articulate a clear strategy to mitigate the adverse effects of exogenous shocks, including the likelihood of a sudden decline in Venezuela-related flows; and (iii) it has to put forward a well-defined structural agenda to address the problems in the energy sector and the pension system.

65. In the case of continued engagement, a successor ECF arrangement appears to provide the most appropriate framework. If there is strong ownership, a successor ECFsupported program could consolidate the achievements of the last two programs. It also could provide a well-defined policy framework for the authorities to move forward with their structural reform agenda in a context of macroeconomic stability. 


\section{Specific Recommendations}

66. What are the necessary ingredients of a possible future Fund-supported program? The design of a possible successor program should be shaped by the lessons of previous programs. In this context, having strong ownership is a critical priority for successful outcomes. The program design should involve at early stages extensive outreach efforts to facilitate discourse among the main social and civic organizations to enhance transparency and develop broad-based ownership. In addition, it would be important to expand the dialogue with the authorities to the highest political level to generate strong support to difficult areas of the structural program. The prospective arrangement should have streamlined and well-targeted conditionality focused on areas where the authorities assume clear ownership. It should also clearly outline potential risks to stability, discuss their implications for the implementation, and set expectations appropriately.

\section{The successor program should build on the macroeconomic stability already} achieved. The macroeconomic program needs to be flexible in incorporating the necessary mechanisms to cope with the various exogenous shocks that periodically affect Nicaragua. In this context, the program should have a well-defined contingency plan to respond to a sudden stop of Venezuela-related inflows. Moreover, it is critical to continue to augment fiscal buffers and strenghten the international reserves position. In particular, fiscal discipline would require eliminating off-budget expenditures financed with temporary flows. In light of the experience of previous programs, quantitative conditionality would have to ensure that changes in the public wage bill are determined in the context of a comprehensive medium-term wage policy consistent with fiscal sustainability. In addition, the fiscal program should be geared towards ensuring debt sustainability, while safeguarding social and other priority expenditures.

\section{A possible future program also would have to focus on a few critical structural} reforms. As the discussion in the previous section showed, promoting higher growth and achieving significant reduction in poverty will require a comprehensive set of reforms. However, in light of the lessons from the previous programs, it would be better to concentrate on a few, well-defined structural areas with the highest pay-off in terms of stability and growth outcomes. Specifically, the core of structural benchmarks needs to focus on the reforms of the energy sector and pension system given the pressing challenges they pose for macroeconomic stability and growth. The program should also seek ways to advance reforms in other macro-critical areas, including monetary and financial sector, and governance.

\section{The prospective program should also emphasize the necessity of further} improvements in transparency and use of foreign aid flows, including those from Venezuela. The program needs to find ways to take account of the quasi-fiscal spending undertaken by CARUNA in the fiscal framework. In addition, it should carefully assess the implications of CARUNA's plans with respect to investment and social programs for real activity, fiscal contingencies, and cost of subsidies.

70. It would be essential to maintain close collaboration with other IFIs and support the program with extensive technical assistance. Since most of the structural reforms are outside the core expertise of the Fund, collaboration and close coordination with other IFIs would be 
critical to ensure appropriate division of labor. Fund TA should continue supporting the objectives of the structural program.

\section{Risks}

71. There are risks associated with continued Fund engagement. Specifically, program design and implementation need to account for the following risks: (i) Exogenous shocks: A sudden stop of Venezuela-related inflows could lead to significant reserve losses, a sharp deterioration in the current account, and pressures on the fiscal accounts. In addition, Nicaragua is inherently vulnerable to natural disasters and movements in commodity prices; (ii) Large imbalances: High levels of public debt and the external current account deficit could threaten economic stability if not kept under control. Given the high level of dollarization, financial stability is quite sensitive to changes in confidence; (iii) Policy slippages: Uneven implementation of macroeconomic and structural policies could undermine economic stability; (iv) Weak institutions and governance: The lack of progress in institutional reforms and governance could threaten economic stability over the medium term, and also constitute reputational risk for the Fund. 


\section{Appendix I. Nicaragua: Reflections of the 2007 EPA Recommendations on the 2007 ECF Program}

\section{EPA: Recommendations}

Energy sector policy. Undertake comprehensive energy sector reform with the required legal and regulatory changes. Reform strategy should envisage the removal of controls on the spot market and limits on margins in the oil industry, an automatic price adjustment mechanism and elimination of discretion by the regulator. In addition, facilitate a reduction in distribution losses, including legal enforcement of payment claims, and the removal of legal and regulatory constraints to investment in hydro-electric power. Cooperate with the World Bank and the IDB in setting reform priorities in the energy sector.

Governance and business climate. Strengthen governance. Improve transparency in the public sector, undertake measures to strengthen the capability and independence of the Comptroller General's Office, and improve the quality and independence of the judiciary.

Pension system. Undertake pension reform to establish a fiscally sustainable pension system over the medium term. Implement a parametric reform of the system by increasing contribution rates and/or decreasing benefits.

Wage policy. Establish a transparent medium term wage policy consistent with the objectives of fiscal sustainability and equity compared with the private sector.

Central bank. Undertake steps to improve Central bank independence and the monetary policy framework.

Fiscal Responsibility Law (FRL). Design a medium-term fiscal strategy less vulnerable to political pressures by adopting a Fiscal Responsibility Law (FRL) (The Fund has been assisting the authorities at the technical level, but political consensus will be key to adoption of the FRL.)

Municipalities. Increase accountability for the use of mandated transfers to municipalities. It is necessary to undertake administrative measures to restore fisca neutrality as the increase in mandated transfers may have the unintended effect of penalizing pro-poor and growth-oriented spending.

Source: IMF staff reports.

\section{ECF Program: Objectives}

Energy sector reforms, designed with the World Bank and IDB, focus on increasing capacity, reducing losses, and implementing the regulatory framework: (i) increasing capacity: adding in new capacity during 200708; (ii) reducing losses: establishing criminal penalties to reduce electricity theft, implement a pilot program to improve electricity metering, and conduct a diagnostic assessment to determine the causes of technical and non-technical loses; and (iii) implementing regulatory framework: authorize monthly adjustment in tariffs when justified by cost changes and publish the formula and methodology used to calculate tariff changes.

Governance: Improve PFM and BCN framework, judiciary reform, and land registration system. Business climate: The new PRSP to elaborate the agenda to promoting private investment, improving investment climate, enhance competitiveness, favoring an export orientation, and setting up a one-stop agency for new business regulatory approvals

Complete actuarial study on the system to improve its financial position, formulate recommendations for reforms by end 2008, and restore the balance between contributions and benefits.

Develop a medium-term public sector wage policy by mid-2008 (drawing on the recent World Bank public expenditure review).

Strengthen the mandate and functions of the BCN to improve the design and implementation of monetary and exchange rate policy. Complete an evaluation of the central bank's balance sheet before the first review following which additional measures to strengthen the financial position of the central bank may be considered.

FRL itself was not included in the program since the authorities felt that it is premature to move forward with it. Instead, the program focused on the following items: (i) develop multi-year strategy to strengthen PFM; (ii) finalize new budget classification and chart of account manuals, and increase poverty-related spending; (iii) strengthen tax and customs administration, including plan to reduce still extensive tax incentives and broaden the base of the personal income tax.

Implement administrative changes to improve the accountability and transparency of the fiscal operation of municipalities, and assign spending responsibility to municipalities. Improve the monitoring and control transfers to municipalities. 
Appendix II. Nicaragua: Major Events During the 2007-11 ECF Program

\begin{tabular}{ll}
\hline \multicolumn{1}{c}{ Year } & Events / Shocks \\
\cline { 2 - 2 } January & Request for ECF Arrangement \\
June & The Sandinista government takes office \\
October & Commodity price shock \\
November & Hurricane Felix \\
$\mathbf{2 0 0 8}$ & Heavy rainfall and floods \\
Continued & First Review \\
April & Commodity price shock \\
September & Suspension of service on public bonds (CENIs) \\
November & Global financial crisis \\
& Municipal Elections \\
$\mathbf{2 0 0 9}$ & Political tensions and suspension of donor flows \\
Continued & due to allegations of electoral fraud \\
$\mathbf{2 0 1 0}$ & Second and Third Reviews \\
May & Fourth and Fifth Reviews \\
October & Announcement of wage bonus \\
November & Heavy rainfall \\
$\mathbf{2 0 1 1}$ & Commodity price shock \\
November & Sixth Review (April) and Seventh Review (October) \\
& Presidential Elections \\
\hline Sources: & Allegations of electoral fraud by opposition and donors \\
\hline
\end{tabular}

Sources: IMF staff reports, 2007-11. 
Appendix III. Nicaragua: ECF-Supported Program Structural Reform Agenda, 2007-11

\begin{tabular}{|c|c|c|c|c|c|c|c|}
\hline & \multirow[b]{2}{*}{$\begin{array}{l}\text { Introduced } \\
\text { at the time of }\end{array}$} & \multirow[b]{2}{*}{$\begin{array}{l}\text { Reform } \\
\text { type }\end{array}$} & \multicolumn{5}{|c|}{ Status of Conditionalities } \\
\hline & & & 1st Review & $\begin{array}{l}\text { 2nd \& 3rd } \\
\text { Reviews }\end{array}$ & $\begin{array}{l}\text { 4th \& 5th } \\
\text { Reviews }\end{array}$ & 6th Review & 7th Review \\
\hline \multicolumn{8}{|l|}{ Energy } \\
\hline $\begin{array}{l}\text { Introduce measure establishing criminal penalities to discourage fraud in the } \\
\text { consumption of electricity }\end{array}$ & ECF Request & PC & $\begin{array}{l}\text { Met with } \\
\text { delay }^{1 /}\end{array}$ & & & & \\
\hline $\begin{array}{l}\text { Prepare a diagnostic assessment of the causes for the technical and nontechnical } \\
\text { distribution losses including recommendations for reducing them }\end{array}$ & ECF Request & SB & $\begin{array}{l}\text { Met with } \\
\text { delay }^{1 /}\end{array}$ & & & & \\
\hline Publish the formula for adjusting electricity tariffs in response to changes in costs & ECF Request & SB & $\mathrm{Met}^{1 /}$ & & & & \\
\hline $\begin{array}{l}\text { Ensure that the tariff schedule covers the cost of generating and distributing electricty } \\
\text { as required by the law }\end{array}$ & ECF Request & SB & $\mathrm{Met}^{2 \prime}$ & & & & \\
\hline Introduce new tariff schedule to covers distribution fees as required by the law & 1st Review & SB & $\mathrm{Met}^{2 \prime}$ & & & & \\
\hline \multicolumn{8}{|l|}{ Fiscal Stance (quantitative) } \\
\hline Approval of the 2008 budget consistent with a CPS deficit of $1.8 \%$ of GDP & ECF Request & PC & $\begin{array}{l}\text { Met with } \\
\text { delay }^{1 /}\end{array}$ & & & & \\
\hline Approval of the 2008 budget supplement consistent with a CPS deficit of $1.8 \%$ of GDP & 1st Review & PC & & $\mathrm{Met}^{1 /}$ & & & \\
\hline Submission to Assembly of a draft 2009 budget consistent with program objectives & 1st Review & PC & & $\mathrm{Met}^{1 /}$ & & & \\
\hline $\begin{array}{l}\text { Approval by Assembly of agreed } 2010 \text { budget consistent with a CPS deficit of } 3.2 \% \text { of } \\
\text { GDP }\end{array}$ & $\begin{array}{l}\text { 2nd \& 3rd } \\
\text { Reviews }\end{array}$ & SB & & & $\begin{array}{l}\text { Met with } \\
\text { delay }^{2 /, 3 /}\end{array}$ & & \\
\hline $\begin{array}{l}\text { Submission to National Assembly of a supplementary Budget for } 2010 \text { consistent with } \\
\text { the program }\end{array}$ & $\begin{array}{l}\text { 4th \& 5th } \\
\text { Reviews }\end{array}$ & PA & & & $\begin{array}{l}\text { Met with } \\
\text { delay }^{2 /, 3 /}\end{array}$ & & \\
\hline $\begin{array}{l}\text { Submission to National Assembly of a Budget for } 2011 \text { consistent with the program } \\
\text { objectives (same above) }\end{array}$ & $\begin{array}{l}\text { 4th \& 5th } \\
\text { Reviews }\end{array}$ & PA & & & $\mathrm{Met}^{1 /}$ & & \\
\hline Approval by Assembly of agreed tax reform yielding at least $0.7 \%$ of GDP & $\begin{array}{l}\text { 2nd \& 3rd } \\
\text { Reviews }\end{array}$ & SB & & & $\mathrm{Met}^{1 /}$ & & \\
\hline \multicolumn{8}{|l|}{ PFM } \\
\hline $\begin{array}{l}\text { Prepare an action plan for strengthening the public sector financial administration } \\
\text { system }\end{array}$ & ECF Request & PC & $\mathrm{Met}^{1 /}$ & & & & \\
\hline Finalize the revision of the budget Classification system and the Chart of account & ECF Request & SB & & $\begin{array}{l}\text { Met with } \\
\text { delay }^{4 /}\end{array}$ & & & \\
\hline $\begin{array}{l}\text { Initiate publication of monthly report monitoring the physical execution of public } \\
\text { investment program }\end{array}$ & $\begin{array}{l}\text { 2nd \& 3rd } \\
\text { Reviews }\end{array}$ & SB & & Pending & Pending & Pending & Pending \\
\hline $\begin{array}{l}\text { Complete study assessing the scope for productivity gains and rationalizing government } \\
\text { employment practices }\end{array}$ & $\begin{array}{l}\text { 4th \& 5th } \\
\text { Reviews }\end{array}$ & SB & & & & & $\begin{array}{l}\text { Met with } \\
\text { delay }^{4 /}\end{array}$ \\
\hline
\end{tabular}


Nicaragua: ECF-Supported Program Structural Reform Agenda, 2007-11 (continued)

\begin{tabular}{|c|c|c|c|c|c|c|c|}
\hline & \multirow[b]{2}{*}{$\begin{array}{l}\text { Introduced } \\
\text { at the time of }\end{array}$} & \multirow[b]{2}{*}{$\begin{array}{l}\text { Reform } \\
\text { type }\end{array}$} & \multicolumn{5}{|c|}{ Status of Conditionalities } \\
\hline & & & 1st Review & $\begin{array}{l}\text { 2nd \& 3rd } \\
\text { Reviews }\end{array}$ & $\begin{array}{l}\text { 4th \& 5th } \\
\text { Reviews }\end{array}$ & 6th Review & 7th Review \\
\hline \multicolumn{8}{|l|}{ Tax administration } \\
\hline Adopt measures to strengthen tax administration & ECF Request & SB & Pending $^{1 /}$ & Pending & Pending & Pending & Pending \\
\hline \multicolumn{8}{|l|}{ Pension system } \\
\hline Complete the study on the actuarial status of the pension system & ECF Request & SB & $\begin{array}{l}\text { Met with } \\
\text { delay }^{1 /}\end{array}$ & & & & \\
\hline $\begin{array}{l}\text { Publication of technical proposal on options to reform the pension system and reduce } \\
\text { its actuarial gap (same above) }\end{array}$ & $\begin{array}{l}\text { 4th \& 5th } \\
\text { Reviews }\end{array}$ & PA & & & $\begin{array}{l}\text { Met with } \\
\text { delay }^{3 /}\end{array}$ & & \\
\hline $\begin{array}{l}\text { Finalize technical proposal on options to reform the pension system and reduce its } \\
\text { actuarial gap }\end{array}$ & $\begin{array}{l}\text { 2nd \& 3rd } \\
\text { Reviews }\end{array}$ & SB & & & $\begin{array}{l}\text { Met with } \\
\text { delay }^{3 \prime}\end{array}$ & & \\
\hline \multicolumn{8}{|l|}{ Monetary } \\
\hline $\begin{array}{l}\text { Complete assessment of the financial position of the } \mathrm{BCN} \text { and make recommendations } \\
\text { to strengthen its finances }\end{array}$ & ECF Request & SB & & $\begin{array}{l}\text { Met with } \\
\text { delay }^{3 \prime}\end{array}$ & & & \\
\hline Approval of renogotiation with banks by the Central Bank Board & 1st Review & PC & & $\begin{array}{l}\text { Met with } \\
\text { delay }^{1 \prime}\end{array}$ & & & \\
\hline Submission of the Central Bank Board nominees to Assembly & 1st Review & PA & $\operatorname{Met}^{1 /}$ & & & & \\
\hline $\begin{array}{l}\text { Communicate to affected banks decision to gradually apply International Reporting } \\
\text { Standards on newly issued bonds }\end{array}$ & 1st Review & PA & $\operatorname{Met}^{1 /}$ & & & & \\
\hline Submission of action plans by affected banks to comply with prudential norms & 1st Review & PA & $\operatorname{Met}^{1 /}$ & & & & \\
\hline \multicolumn{8}{|l|}{ Microfinance institutions } \\
\hline $\begin{array}{l}\text { Assembly approval of a regulatory framework for institutions operating in the } \\
\text { microfinance industry }\end{array}$ & 6th Review & SB & & & & & $\operatorname{Met}^{1 /}$ \\
\hline \multicolumn{8}{|l|}{ Social } \\
\hline $\begin{array}{l}\text { Initiate bi-annual publication of the principal social indicators for health, education, and } \\
\text { water and sanitation sectors }\end{array}$ & ECF Request & SB & & $\begin{array}{l}\text { Met with } \\
\text { delay }^{3 /}\end{array}$ & & & \\
\hline \multicolumn{8}{|l|}{ Transparency } \\
\hline Publication of a report on all official aid flows with information through end-2007 & 1st Review & PA & Pending & & & & \\
\hline Publication of a report on all official aid flows with information through end-2008 & 1st Review & SB & & $\begin{array}{l}\text { Met with } \\
\text { delay }^{1 /}\end{array}$ & & & \\
\hline Publication of aid report with fuller disclosure on use of aid flows & $\begin{array}{l}\text { 4th \& 5th } \\
\text { Reviews }\end{array}$ & SB & & & & $\operatorname{Met}^{1 /}$ & \\
\hline
\end{tabular}

Sources: IMF staff reports, 2007-11.

${ }^{1 /}$ No change (in content, status, and timeline), ${ }^{2 /}$ Modified content, ${ }^{3 /}$ Modified status, ${ }^{4 /}$ Modified timeline

PC: Performance Criteria, SB: Structural Benchmark, PA: Prior Action 
Appendix IV. Nicaragua: Millenium Development Goals, 1990,1995, and, 2000-2010

\begin{tabular}{|c|c|c|c|c|c|}
\hline & 1990 & 1995 & 2000 & 2005 & 2010 \\
\hline \multicolumn{6}{|l|}{ Goal 1: Eradicate extreme poverty and hunger } \\
\hline Employment to population ratio, $15+$, total $(\%)$ & $\ldots$ & 53.8 & 56.2 & 58.1 & 59.7 \\
\hline Employment to population ratio, ages $15-24$, total (\%) & $\ldots$ & 46.4 & 46.2 & 46.8 & 45.9 \\
\hline Poverty gap at $\$ 1.25$ a day (PPP) $(\%)$ & $5.6^{1993}$ & $3.1^{1 / 1998}$ & $3.7^{2001}$ & 2.4 & $\ldots$ \\
\hline Malnutrition prevalence, weight for age ( $\%$ of children under 5 ) & $\ldots$ & $\ldots$ & $7.8^{12001}$ & 4.3 & $5.7^{12007}$ \\
\hline Prevalence of undernourishment (\% of population) & $\ldots$ & $\ldots$ & $25.0^{12001}$ & $\ldots$ & $19.0^{12008}$ \\
\hline \multicolumn{6}{|l|}{ Goal 2: Achieve universal primary education } \\
\hline Primary completion rate, total (\% of relevant age group) & 39.2 & 49.0 & 66.2 & 74.6 & 80.9 \\
\hline School enrollment, primary (\% net) & 67.0 & 72.9 & 79.2 & 88.0 & 92.5 \\
\hline \multicolumn{6}{|l|}{ Goal 3: Promote gender equality and empower women } \\
\hline Proportion of seats held by women in national parliaments $(\%)$ & 15.0 & 11.0 & 10.0 & 20.7 & 20.7 \\
\hline Ratio of girls to boys in primary and secondary education (\%) & $119^{/ 1989}$ & $\ldots$ & 105.2 & 101.9 & 101.6 \\
\hline \multicolumn{6}{|l|}{ Goal 4: Reduce child mortality } \\
\hline Immunization, measles (\% of children ages $12-23$ months) & 82.0 & 85.0 & 86.0 & 95.0 & 99.0 \\
\hline Mortality rate, infant (per 1,000 live births) & 51.6 & 42.0 & 34.4 & 28.1 & 22.6 \\
\hline Mortality rate, under- 5 (per 1,000$)$ & 68.0 & 53.6 & 42.7 & 34.1 & 26.9 \\
\hline \multicolumn{6}{|l|}{ Goal 5: Improve maternal health } \\
\hline Births attended by skilled health staff (\% of total) & $\ldots$ & $61.0^{\prime 1993}$ & $66.9^{12001}$ & $73.7^{12007}$ & $\ldots$ \\
\hline Contraceptive prevalence (\% of women ages $15-49$ ) & $\ldots$ & $48.7^{1993}$ & $68.6^{12001}$ & $72.4^{12007}$ & $\ldots$ \\
\hline Maternal mortality ratio (modeled estimate, per 100,000 live & 170 & 150 & 130 & 110 & 95 \\
\hline \multicolumn{6}{|l|}{ Goal 6: Combat HIVIAIDS, malaria, and other diseases } \\
\hline Incidence of tuberculosis (per 100,000 people) & 108 & 85 & 68 & 53 & 42 \\
\hline Prevalence of HIV, total (\% of population ages 15-49) & 0.1 & 0.1 & 0.1 & 0.2 & $0.2^{12009}$ \\
\hline Tuberculosis case detection rate (\%, all forms) & 66 & 72 & 70 & 66 & 100 \\
\hline \multicolumn{6}{|l|}{ Goal 7: Ensure environment sustainability } \\
\hline $\mathrm{CO} 2$ emissions (metric tons per capita) & 0.60 & 0.60 & 0.70 & 0.70 & $0.76^{2008}$ \\
\hline Forest area ( $\%$ of land area) & 37.5 & $\ldots$ & 31.7 & 28.8 & 25.9 \\
\hline Improved sanitation facilities (\% of population with access) & 43.0 & 44.0 & 48.0 & 50.0 & 52.0 \\
\hline Improved water source (\% of population with access) & 74.0 & 77.0 & 80.0 & 83.0 & 85.0 \\
\hline Terrestrial protected areas ( $\%$ of total land area) & 15.4 & 29.2 & 36.7 & 36.7 & 36.7 \\
\hline \multicolumn{6}{|l|}{ Goal 8: Develop a global partnership for development } \\
\hline Internet users (per 100 people) & 0 & 0 & 1.0 & 2.6 & 10.0 \\
\hline Mobile cellular subscriptions (per 100 people) & 0 & 0 & 1.8 & 20.6 & 65.1 \\
\hline
\end{tabular}

Source: Millennium Development Goals, World Bank.

Note: A superscript indicates the nearest available data point for the respective column (year).

Goal 1. Halve, between 1990 and 2015, the proportion of people whose income in less than $\$ 1$ a day and the proportion of people who sufer from hunger. Achieve full and productive employment and decent work for all, including women and young people.

Goal 2. Ensure that, by 2015, children everywhere, boys and girls alike, will be able to complete a full course of primary schooling.

Goal 3. Eliminate gender disparity in primary and secondary education no later than 2015.

Goal 4. Reduce by two-thirds, between 1990 and 2015, the under-five mortality rate.

Goal 5. Reduce by three quarters, between 1990 and 2015, the maternal mortality ratio. Achieve, by 2015, universal access to reproductive health.

Goal 6 . Have halted by 2015 and begun to reverse the spread of HIVIAIDS, malaria and other major diseases. Achieve, by 2010 , universal access to treatment for HIVIAIDS for all those who need it.

Goal 7. Integrate the principles of sustainable development into country policies and programmes and reverse the loss of environmental resources. Reduce biodiversity loss, achieving, by 2010 , a significant reduction in the rate of loss.

Goal 8. Address the special needs of the least developed countries, landlocked countries and small island developing states. Develop further an open, rule-based, predictable, non-discriminatory trading and financial system. Deal comprehensively with developing countries' debt. In cooperation with the private sector, make available the benefits of new technologies, especially information and communications. 


\section{Annex I. The Views of the Authorities}

Discussions of the EPA were held in HQ on April 20, 2012 with Mr. Guevara (governor of Nicaragua's central bank and former minister of finance), Mr. Acosta (minister of finance), and other senior officials, and in Managua during May 14-17, 2012 with current and former authorities. Their comments are summarized below.

The Nicaraguan authorities noted that the Fund-supported program was successful in a number of dimensions:

- The program played an important role in maintaining macroeconomic stability and in helping to push forward significant reforms. The Fund-supported program helped guide policies during an extremely challenging period. Nicaragua registered sustained output growth (except in 2009), increased its exports, and attracted substantial FDI during 2007-11. Moreover, the program catalyzed reforms in financial regulation, central bank governance, tax policy, and the energy sector.

- The program design took into account Nicaragua's social and economic conditions. As a result, it was able to identify key implementation risks. Since its design was built on the authorities' 2007 Economic and Financial Program (PEF) and the National Development Plan, it emphasized social progress while preserving macroeconomic stability. The macroeconomic program was flexible and able to accommodate changes in the global economic environment. The structural program was properly sequenced.

- $\quad$ TA support played a key role in accompanying reforms. TA support, particularly through CAPTAC-DR, was vital in strengthening key institutions (the Tax and Customs Administration, the BCN, the Superintendent Office, and the Social Security Administration). Moreover, TA support was critical in helping the implementation of structural reforms envisaged in the program.

\section{However, the authorities also highlighted some concerns:}

- The program could have been more effective in supporting growth during the global financial crisis. The second review was delayed due to the uncertainties associated with the global crisis, despite an early policy response. The authorities perceive that Nicaragua did not receive consistent treatment from the Fund during the crisis compared with other member countries. Specifically, Nicaragua was asked to implement procyclical fiscal policies during the crisis while most other member countries were able to employ countercyclical measures. The program could have led to better outcomes if Nicaragua had been able to have additional, and more flexible, access to Fund resources. Moreover, it was clearly necessary for the Fund to consider expanding facilities available to low-income countries like Nicaragua especially during the global financial crisis. 
- The assessment of program ownership would be different if seen within a broader context. It was natural to observe delays and challenges during the program because the new administration needed to seek a broad consensus to implement reforms, in the context of an adverse external environment. They adjusted the fiscal program multiple times in 2009 (during the completion of the combined second and third reviews) and 2010 (during the completion of the combined fourth and fifth reviews) indicating that they were serious about the program implementation. The pension reform was delayed because it was necessary for the authorities to study various reform options before seeking a broad-based consensus. In addition, the authorities' ownership was stronger in the 2007-11 program than that in earlier programs.

- With regard to staff's insistence in considering a strategy for a sudden decline in Venezuela-related flows, the authorities' position is that the analysis should have been broader, reflecting Nicaragua's needs for donor support. In the case of Venezuela, given the strong partnership between Nicaragua and Venezuela, the probability of a sudden decline in the flows was extremely low. Even if the flows unexpectedly fell, the impact could be manageable in the short-term given the large deposits (of Venezuela-related flows) in the financial system. If such an unlikely scenario were to materialize, it would be necessary to make some adjustments in subsidies and social programs funded by the flows from Venezuela. However, this adjustment could take place gradually without a large adverse impact on the fiscal position.

- $\quad$ Nicaragua missed stronger support during the financial crisis because the World Bank and other bilateral donors reduced their financial assistance. Nicaragua was able to receive additional funding from the IDB and a contingent credit line from the CABEI in 2009. However, the impact of the global financial crisis could have been much milder if support from the World Bank and other bilateral donors had continued. In particular, the suspension of budget-support loans from the World Bank after 2008 was unfortunate and led to significant challenges in advancing social programs.

- Improved communication between the authorities and staff could have been helpful. In this context, there were three major issues. First, high staff turnover in Nicaragua mission teams during the program was a concern. Second, better communication across departments in the Fund was necessary in order to have a unified policy front on program related matters. Third, it was imperative to prevent leaks of program-related documents to the press.

The authorities acknowledged that Nicaragua has an unfinished reform agenda. In particular, the reform process would need to continue in the following areas: the pension system, energy sector, revenue collection and public sector wage policy. They indicated that although there was significant progress in increasing capacity and reducing losses in the energy sector, the reform of the regulatory framework would still be a challenging task.

The authorities also indicated that they were interested in a successor program. They noted that a new Fund-supported program would help Nicaragua to continue to implement sound macroeconomic policies, eliminate vulnerabilities, reduce poverty and address the unfinished reform agenda. The future collaboration could be more successful if it were complemented by additional TA support. 


\section{Annex II. The Views of Other Stakeholders in Nicaragua}

Discussions of the EPA with other stakeholders (representatives of international financial organizations, business community, financial sector, and civil society) were held in Managua during May 14-17, 2012. Below is a summary of their views.

Other stakeholders acknowledged that the Fund-supported program helped the authorities pursue disciplined macroeconomic policies and undertake important reforms. The program served Nicaragua during a transition period as the new administration and other stakeholders were in the process of establishing a consensus on economic policies. Despite the prevalence of multiple domestic and external shocks during 2007-11, the Fund-supported program was able to help guide policies and ultimately led to successful outcomes. It helped to preserve macroeconomic stability, support a favorable investment climate, enhance business confidence, and play a significant role in advancing major reforms.

Representatives of the business and financial community argued that while a sudden decline in Venezuela-related flows was a low probability event, it would be critical to devise a strategy to mitigate its impact. They noted that the authorities could cope with such a contingency in the short term because of the large deposits of Venezuela-related flows in the banking system. However, they indicated that it would be important to have a clear strategy to lessen the negative effects of a potential decline in flows and to consider how the government would adjust its fiscal accounts in light of the large subsidies and social programs funded by these flows. Other stakeholders noted that the Fund-supported program played a major role in increasing transparency of the flows. Any future program with the Fund would need to continue improving the transparency and governance of the flows while working with the authorities to make sure that Nicaragua would be ready for the possibility of an unexpected decline in the flows.

There was agreement that Nicaragua has to embark on a wide-ranging reform program to achieve better economic growth and poverty reduction outcomes. They acknowledged that labor and product market informality hampers growth in the real and financial sectors. In addition, they noted that governance quality was a serious concern. There was awareness that it would be difficult to improve the quality of institutions in a short time. However, it was noted that Nicaragua has to develop a comprehensive strategy to start making progress in reducing informality and improving governance quality given their obvious effects on long-term growth.

It was argued that Nicaragua would benefit greatly from a new Fund-supported program. A new program with the Fund would signal policy continuity and build on the successes of the last two arrangements. In addition, it would help maintain macroeconomic stability and continue to play a catalytic role in advancing the reform agenda. The structural program would need to focus on the reforms of the pension system, the energy sector, and tax policy. In addition, the prospective program needs to emphasize growth-augmenting policies. 


\section{Annex III. Statement of the Authorities}

The authorities provided the following statement on the program performance and EPA report.

\section{Main comments on the 2007-11 ECF-supported program}

1. The ECF with the IMF largely achieved its objectives, especially considering that the major risks identified in 2007 materialized during the four years of the program (prices for commodities rose, particularly oil; and external demand fell in the context of the global financial crisis placing strong pressure on spending, mainly for subsidies). Despite the foregoing, the country maintained a stable macroeconomic framework, made space for an increase in pro-poor spending, and revitalized growth. Nevertheless, Nicaragua's major long-term challenges remain, especially in terms of the need to increase growth and reduce poverty, as well as risks relating to the large trade deficit and the country's vulnerability to external shocks.

2. The IMF response to the international crisis. Although the arrangement with the IMF supported the government's efforts to maintain macroeconomic stability, the IMF's response in the context of the global financial crisis was too little, too late. During the period of greatest uncertainty about the international environment, IMF staff were unwilling to complete the review of the Nicaragua program. The argument was that this uncertainty was reflected in the fiscal program, making it difficult to set quantitative targets. From the country's point of view, it was precisely the uncertainty about international prospects that ought to have translated into a more flexible position on the part of the staff. Although Nicaragua was possibly the only country in the region with an IMF program prior to the crisis, the other Central American countries were able to negotiate new programs with the IMF at the beginning of 2009; in the case of Nicaragua the second and third reviews were only completed in November 2009.

3. The IMF loan disbursements under the ECF 2007-2011 were lowered to US $\$ 122.9$ million (SDR 78 million), compared to US\$142 million (SDR 97.5 million) under the previous program (2002-2006). This occurred despite the eruption of a serious global crisis and shocks to the terms of trade as a result of higher and more volatile oil prices.

4. Turnover in IMF staff. As with other programs, one problem with the ECF 2007-2011 was the high staff turnover. There were four mission chiefs during the program, and even higher turnover at the staff level. During the time of the global financial crisis, there was a period when the IMF staff were clearly insufficient, which may have had an impact on the delay in the review.

5. Room for improvement in communication between different IMF departments. During the course of the program, there were clearly differences of opinion at times between different IMF departments. On these occasions, however, the significant effort made by the staff of the Western Hemisphere Department was much appreciated in building consensus while presenting the national position. 
6. Good technical assistance support. One element of the ECF to be underscored is that the IMF was open to addressing technical assistance needs within the program, making adequate use of resources channeled through the Regional Technical Assistance Center for Central America, Panama and the Dominican Republic (CAPTAC-DR).

7. Information leaks. An important fact about the ECF is that, on at least two occasions, the national media gained access to documents relating to the Board meetings on Nicaragua prior to their formal discussion and without authorization by the national authorities. This was reported to the IMF staff, management and the Executive Director representing Nicaragua. In this respect, there is evidently room for improvement in controls on the circulation of potentially sensitive documents.

\section{Comments on the EPA report}

The document provides a good summary of progress and results under the Extended Credit Facility 2007-2011. However, improvements could be made with respect to the following:

1. Excessive bias in highlighting a lack of ownership of the program on the part of the authorities, rather than acknowledging that, relative to other programs, this one had the highest degree of ownership.

2. A partial analysis of the weaknesses and constraints on program progress from the point of view of the country is presented; however, there is no mention of the room for improvement in design, responsiveness, and instruments made available by the Fund.

3. Reference is made to value judgments on political events that are beyond the remit of an institution such as the Fund. 


\section{References}

Calderon, C., and V. Poggio, 2012, "Trade and Economic Growth: Evidence on the Role of Complementarities for the DR-CAFTA Countries," Financial Development in Latin America and the Caribbean, the World Bank, pp. 83-122.

Chang, R., L. Kaltani, and N.V. Loayza, 2009, "Openness can be good for growth: The role of policy complementarities," Journal of Development Economics, Vol. 90, No. 1, pp. 33-49.

Edwards, S., 1992, "Real Exchange Rates, Competitiveness, and Macroeconomic Adjustment in Nicaragua," Working Paper, UCLA.

Harberger, A.C., 2007, “The Nicaraguan Economy: Situation and Prospects," remarks presented at a conference sponsored by USAID, Managua, Nicaragua.

International Monetary Fund, 2007, "Nicaragua-Request for a Three-Year Arrangement Under the Poverty Reduction and Growth Facility" (unpublished).

_ 2007, "Fiscal Response to Scaled-Up Aid: Macro-Fiscal and Expenditure Policy Challenges" prepared by the Fiscal Affairs Department (In consultation with other departments).

— , 2007, "Nicaragua-Ex Post Assessment of Longer-Term Program Engagement" (unpublished)

— 2008, "Nicaragua-First Review Under the Three-Year Arrangement Under the Poverty Reduction and Growth Facility, Review of Financing Assurances, Request for Waiver of Nonobservance of Performance Criteria and Augmentation of Access" (unpublished).

— 2009, "Nicaragua-Second and Third Reviews Under the Three-Year Arrangement Under the Poverty Reduction and Growth Facility, Request for Waiver of Nonobservance of Performance Criteria and Rephasing of Purchases, and Financing Assurance Review" (unpublished).

—_ 2010, "Longer-Term Program Engagement—Revised Guidance Note" (unpublished).

— 2010, "Nicaragua-Fourth and Fifth Reviews Under the Extended Credit Facility, Request for Extension of the Arrangement, Rephasing of Access, and Waiver of Nonobservance of Performance Criterion, and Financing Assurance Review" (unpublished).

— , 2010, "Nicaragua-Article IV Consultation” (IMF Public Information Notice No. 10/83).

_ 2011, "Nicaragua-Sixth Review Under the Extended Credit Facility and Financing Assurance Review" (unpublished). 
2011, "Nicaragua-Seventh Review Under the Extended Credit Facility and Financing Assurance Review" (unpublished).

Kose, M.A., E. S.Prasad, and A. D. Taylor, 2011, "Thresholds in the process of international financial integration," Journal of International Money and Finance, Vol. 30, No. 1, pp. 147-79.

Ocampo, J. A., 1992, “Hyperinflation and Stabilization in Nicaragua,” Fedessarrollo, Bogota, Colombia, Working Paper.

Swiston, A. and L. Barrot, 2011, "The Role of Structural Reforms in Raising Economic Growth in Central America," IMF Working Paper, No: 11/248. 


\section{INTERNATIONAL MONETARY FUND}

Public Information Notice

EXTERNAL

RELATIONS

DEPARTMENT

Public Information Notice (PIN) No. 12/75

FOR IMMEDIATE RELEASE

International Monetary Fund

July 12,2012

$70019^{\text {th }}$ Street, NW

Washington, D. C. 20431 USA

\section{IMF Executive Board Concludes 2012 Article IV Consultation with Nicaragua}

On June 27, 2012, the Executive Board of the International Monetary Fund (IMF) concluded the Article IV consultation ${ }^{1}$ and discussed the Ex Post Assessment of Longer-Term Program Engagement (EPA) ${ }^{2}$ with Nicaragua.

\section{Background}

Macroeconomic developments in Nicaragua have been broadly positive since 2010 . Real gross domestic product (GDP) grew on average 4.6 percent during 2010-11, underpinned by robust consumption and investment. Inflationary pressures abated somewhat to 8 percent by end-2011 (from 9.2 percent at end-2010), as world commodity prices eased. Although the external current account deficit widened in 2011 (to 18 percent of GDP), larger capital inflows (mainly sizable foreign direct investment) produced a small surplus in the balance of payments, thus increasing international reserves.

\footnotetext{
${ }^{1}$ Under Article IV of the IMF's Articles of Agreement, the IMF holds bilateral discussions with members, usually every year. A staff team visits the country, collects economic and financial information, and discusses with officials the country's economic developments and policies. On return to headquarters, the staff prepares a report, which forms the basis for discussion by the Executive Board. At the conclusion of the discussion, the Managing Director, as Chairman of the Board, summarizes the views of Executive Directors, and this summary is transmitted to the country's authorities. An explanation of any qualifiers used in summings up can be found here: http://www.imf.org/external/np/sec/misc/qualifiers.htm.
}

${ }^{2}$ An EPA is required for all members having longer-term program engagement with the Fund. EPAs are intended to provide an opportunity to step back from continuing program relations to consider an analysis of the economic problems facing the country, review progress under Fund-supported programs, and draw forward-looking lessons for future Fund engagement. 
The fiscal outturn of 2011 surpassed expectations. The tax reform of 2009 and the strong output recovery boosted tax revenues, while central government spending as a share of GDP remained broadly stable. As a result, the central government recorded a surplus of 0.6 percent of GDP (following a deficit of 1 percent of GDP in 2010), which was primarily used to pay down debts of the state-owned electricity generation company. Elsewhere in the public sector, a deterioration in the fiscal result of the social security system, the municipality of Managua, and the state-owned enterprises was partly offset by a smaller operating deficit of the central bank than in 2010. On net, the consolidated public sector recorded a small surplus for the first time since 2007.

Monetary policy continued to bolster the international reserves position and conditions in the financial system strengthened. The central bank maintained the crawling-peg system, which helped anchor inflation expectations. Banks' liquidity remained ample while credit growth picked up significantly towards the end of the year. Nonperforming loans ratios declined as banks' profitability improved and deposits (in local and foreign currency) rose.

Looking ahead, real GDP growth is expected to slow in 2012 and inflation to rise to between 8 and 9 percent owing to oil price increases. The consolidated public sector is projected to post a deficit in 2012 as some spending pressures resurface, but its fiscal position is expected to improve gradually in the medium term with expenditure restraint at the level of the central government, central bank, and state-owned enterprises. The external current account balance is expected to widen in 2012 on the back of weaker external demand and a larger oil bill, which would reduce moderately the international reserves coverage. Risks to the economic outlook for 2012 are tilted to the downside given Nicaragua's exposure to economic activity abroad.

The Ex Post Assessment (EPA) reviewed Nicaragua's performance under the 2007-11 program supported by an Extended Credit Facility (ECF) arrangement. The EPA concluded that although the Nicaraguan economy was buffeted by a series of adverse shocks between 2007 and 2011, the ECF-supported program was effective in helping the authorities develop an appropriate policy framework to support macroeconomic stability. The program also paved the way for some reforms of the tax system and the energy sector, but it fell short in key areas, such as pensions and public financial management.

\section{Executive Board Assessment}

Executive Directors welcomed Nicaragua's robust economic recovery and favorable macroeconomic performance on the back of sound policies, high export prices, and large investment inflows. Nevertheless, Directors underscored that important macroeconomic and structural challenges remain to be addressed, including widespread poverty and large external imbalances. With downside risks prevailing due to the uncertain global environment, Directors encouraged the authorities to maintain prudent macroeconomic policies and step up the pace of structural reform. 
Directors stressed that fiscal consolidation should be the cornerstone of macroeconomic stability. With wage bonuses and higher electricity subsidies worsening the fiscal outlook for 2012, Directors urged firm expenditure restraint. In the medium term, reforms to strengthen further the revenue effort and to revamp the pension system will be critical, alongside current expenditure restraint, in accommodating higher social and infrastructure spending while maintaining fiscal sustainability. Particularly important will be to widen the tax base by curtailing exemptions.

Directors underscored that reducing external vulnerabilities related to the large external current account deficit will be a key challenge in the period ahead. They supported plans to cut back on oil imports and increase international reserves. They also stressed the importance of reducing the size and improving the composition of the public debt, and encouraged the authorities to step up efforts to obtain debt relief on HIPC terms from non-Paris Club creditors.

Directors urged the authorities to prioritize and address the key structural impediments to growth and poverty reduction. They highlighted the need to strengthen governance and institutions, improve public financial management, reduce labor market informality, and tackle weaknesses in the energy sector.

Directors welcomed the progress in improving banking supervision, reflected in the overall soundness of the financial system. They encouraged concerted action to deal with remaining vulnerabilities, including increased collaboration with regional supervisors. Directors welcomed the creation of a financial intelligence unit, and urged the authorities to seize the opportunity to bring the regime against money laundering and terrorism financing into compliance with international standards.

Directors welcomed the conclusion of the Ex Post Assessment that the Fund's engagement in Nicaragua during 2007-11 contributed to macroeconomic stability. They noted, however, that exogenous shocks and at times weak program ownership led to uneven progress in structural reforms. In light of this, Directors highlighted several lessons for the future. In particular, Directors stressed that policies should have strong ownership by the authorities, structural reforms should be well designed and well targeted, and implementation should be flexible to accommodate unexpected shocks and capacity constraints. 
Public Information Notices (PINs) form part of the IMF's efforts to promote transparency of the IMF's views and analysis of economic developments and policies. With the consent of the country

(or countries) concerned, PINs are issued after Executive Board discussions of Article IV consultations with member countries, of its surveillance of developments at the regional level, of post-program monitoring, and of ex post assessments of member countries with longer-term program engagements. PINs are also issued after Executive Board discussions of general policy matters, unless otherwise decided by the Executive Board in a particular case. 
Nicaragua: Selected Social and Economic Indicators, 2008-13

\begin{tabular}{|c|c|c|c|c|c|c|}
\hline & 2008 & 2009 & 2010 & $\begin{array}{r}2011 \\
\text { Est. }\end{array}$ & $\begin{array}{r}2012 \\
\text { Pro }\end{array}$ & 2013 \\
\hline Real sector & \multicolumn{6}{|c|}{ (Percent) } \\
\hline GDP growth & 2.8 & -1.5 & 4.5 & 4.7 & 3.7 & 4.0 \\
\hline GDP deflator & 15.0 & 3.9 & 6.0 & 11.1 & 8.6 & 7.9 \\
\hline \multicolumn{7}{|l|}{ Consumer price inflation } \\
\hline End of period & 13.8 & 0.9 & 9.2 & 8.0 & 8.6 & 7.5 \\
\hline Period average & 19.8 & 3.7 & 5.5 & 8.1 & 9.2 & 7.9 \\
\hline & \multicolumn{6}{|c|}{ (Percent of GDP; unless otherwise indicated) } \\
\hline \multicolumn{7}{|l|}{ External sector } \\
\hline Current account & -24.6 & -13.4 & -14.7 & -18.0 & -21.4 & -19.0 \\
\hline Exports of goods, f.o.b & 39.7 & 38.5 & 47.9 & 55.6 & 57.2 & 57.7 \\
\hline Imports of goods, f.o.b. & -74.2 & -63.2 & -72.7 & -83.9 & -87.7 & -86.1 \\
\hline Of which: oil & -15.1 & -10.9 & -11.4 & -16.7 & -17.0 & -14.7 \\
\hline Capital and financial account ${ }^{1 /}$ & 24.1 & 19.7 & 17.7 & 18.8 & 21.1 & 20.2 \\
\hline Of which: FDI & 9.8 & 7.0 & 7.7 & 13.3 & 10.6 & 9.6 \\
\hline Gross reserves (US\$ m) $)^{1 /}$ & 1,141 & 1,573 & 1,799 & 1,892 & 1,879 & 1,990 \\
\hline (in months of imports excl. maquilas) & 2.9 & 4.9 & 4.7 & 4.0 & 3.5 & 3.6 \\
\hline \multicolumn{7}{|l|}{ Fiscal sector } \\
\hline \multicolumn{7}{|l|}{ Central government overall } \\
\hline balance, after grants & -1.2 & -2.8 & -1.0 & 0.6 & -0.5 & -0.4 \\
\hline Revenues & 19.0 & 18.9 & 19.6 & 21.1 & 21.5 & 21.6 \\
\hline Expenditures $^{2 /}$ & 23.2 & 24.1 & 23.0 & 23.2 & 24.4 & 23.9 \\
\hline Grants $^{2 /}$ & 2.9 & 2.4 & 2.5 & 2.7 & 2.4 & 1.9 \\
\hline \multicolumn{7}{|l|}{ Combined public sector (CPS) } \\
\hline balance, before grants & -4.6 & -6.5 & -4.0 & -2.9 & -4.7 & -3.5 \\
\hline CPS overall balance, after grants & -1.5 & -3.1 & -1.4 & 0.1 & -2.1 & -1.3 \\
\hline Financing & 1.5 & 3.1 & 1.4 & -0.1 & 2.1 & 1.3 \\
\hline External & 1.9 & 3.9 & 3.3 & 2.6 & 2.9 & 3.3 \\
\hline $\begin{array}{l}\text { Domestic } \\
\text { (including BCN operating balance) }\end{array}$ & -0.3 & -0.8 & -1.9 & -2.7 & -0.8 & -1.8 \\
\hline \multicolumn{7}{|l|}{ Public sector debt } \\
\hline Total & 74.8 & 80.1 & 78.0 & 73.1 & 68.7 & 65.8 \\
\hline Domestic & 19.7 & 21.2 & 19.2 & 17.3 & 13.7 & 11.0 \\
\hline External $^{3 /}$ & 55.1 & 58.9 & 58.8 & 55.8 & 55.1 & 54.8 \\
\hline
\end{tabular}

Sources: Central Bank of Nicaragua; Ministry of Finance; World Bank; and Fund staff estimates and projections.

${ }^{1 /}$ Figures include the SDR105.1 million (US\$165 million) allocation of September 2009.

${ }^{2 /}$ Figures for 2010-13 include off-budget wage bonus.

${ }^{3 /}$ Actual and projection are based on the 2011 DSA Update. Estimates up to 2010 correspond to the legal situation. 